University of Rhode Island

DigitalCommons@URI

Open Access Dissertations

1986

\title{
EFFECT OF THE CONTENT OF MORAL DILEMMAS UPON RESPONSES ON THE DEFINING ISSUES TEST
}

Gail M. Lawson

University of Rhode Island

Follow this and additional works at: https://digitalcommons.uri.edu/oa_diss

\section{Recommended Citation}

Lawson, Gail M., "EFFECT OF THE CONTENT OF MORAL DILEMMAS UPON RESPONSES ON THE DEFINING ISSUES TEST" (1986). Open Access Dissertations. Paper 1074.

https://digitalcommons.uri.edu/oa_diss/1074

This Dissertation is brought to you for free and open access by DigitalCommons@URI. It has been accepted for inclusion in Open Access Dissertations by an authorized administrator of DigitalCommons@URI. For more information, please contact digitalcommons-group@uri.edu. 
EFFECT OF THE CONTENT OF MORAL DILEMMAS UPON RESPONSES ON THE DEFINING ISSUES TEST

BY

GAIL M. LAWSON

A DISSERTATION SUBMITTED IN PARTIAL FULFILLMENT

OF THE REQUIREMENTS FOR THE DEGREE OF

DOCTOR OF PHILOSOPHY

UNIVERSITY OF RHODE ISLAND

1986 


\section{ABSTRACT}

This study investigates the "structured whole" hypothesis of cognitive-moral developmental theory which suggests that there is a general factor of moral stage crosscutting responses to all moral dilemmas which results in a stage-consistent pattern of responses on instruments assessing moral development. In order to assess the effect of the content of moral dilemmas the Defining Issues Test (DIT) was administered to 300 undergraduate students at a mid-sized state university. Results suggest that dilemmas differentially "pull for" or exclude certain levels of moral reasoning providing no support for the "structured whole" hypothesis of cognitive moral development theory. Additional research in the following three areas is necessary in order that the underlying assumptions of cognitive developmental theory be further investigated: determination of the test-retest reliability of DIT stage scores, profile analyses of subjects' responses on the DIT, and evaluation of the effects of both subject and dilemma variables on DIT responses. 


\section{ACKNOWLEDGMENT}

This dissertation is the most demanding project, both intellectually and emotionally, that I have ever undertaken. Without the guidance, encouragement and support of many people, I doubt that my efforts would have met with success.

I am intellectually indebted to Janet Kulberg, my major professor, and the members of my committee, John Boulemetis, Peter Merenda and William Vosburgh. They have all given generously of their time to guide my research. Throughout the entire period during which this dissertation was written, Jane Carey has provided warm friendship and emotional support. Her kindnesses will never be forgotten.

Finally, I would like to thank my husband James for his unconditional love, support and encouragement. Without his unfailing willingness to subjugate his needs and priorities to mine, this dissertation would not have been completed. 


\section{TABLE OF CONTENTS}

Page

ABSTRACT

ACKNOWLEDGMENT

LIST OF TABLES

LIST OF FIGURES

CHAPTER

I. Statement of the Problem

II. Background Theory and Research

The Cognitive Developmental Paradigm

Piaget's simple two-stage model of moral reasoning

Kohlberg's simple six-stage model of moral reasoning

Rest's complex stage model of moral reasoning

The concept of stage in cognitive moral development theory

The Situational Paradigm

Empirical Findings

Research Questions

III. Method

Subjects

Instrument

Procedure

IV. Results

V Discussion 
Page

\section{APPENDICES}

A. Approval Letter: Institutional Review Board 65

B. Defining Issues Test

c. Defining Issues Test Standard Test Instructions 82

D. Tukey (A) Procedure Associated with Levels of Moral Reasoning for Dilemma Issue Rankings and Tukey (A) Procedure Associated with Dilemma

Issue Rankings for Level of Moral Reasoning 


\section{LIST OF TABLES}

Table

1. Classification of Moral Judgment into Levels and Stages of Development

2. Rest's Stages of Moral Judgment

3. Summary of Studies Investigating the Effects of Test Characteristics on Piagetian Dilemmas

4. Student Group Averages on DIT P-Scores

5. Correlations of DIT with Kohlbergian Tests of Moral Judgment

6. Two-Year Changes in DIT P-Scores

7. Means on Pre and Post Tests of the DIT and CCIT for Logic and Ethics Students

8. Test-retest Reliability of the DIT

9. Frequency of Level of Reasoning Cited as Most Important

10. Chi-Square Goodness-of-Fit Test for DIT

Dilemma's X Level of Reasoning

11. Sum of Weighted Issue Rankings on the Heinz, Student, Webster, and Doctor Dilemmas

12. Means and Standard Deviations of Weighted Issue Rankings for the Heinz, Student, Webster, and Doctor Dilemas

13. Summary of $5 \times 4$ Analysis Variance of Issue Rankings by Dilemma by Level of Moral Reasoning

14. Percentage of stage Responses on the DIT for Ten Randomly selected Subjects 


\section{LIST OF FIGURES}

Figure

Page

1. The Complex Stage Model. A disjunctive scale formed by the relative usage of six different stages across development.

2. Graphic Presentation of the Simple Stage Model

3. Sum of Issue Rankings for Levels 2, 3, 4, 5A, and 6 for the Heinz, student, Webster, and Doctor Dilemmas.

4. Sum of Issue Rankings of Heinz, Student, Webster, and Doctor Dilemmas for Moral Reasoning Levels 2 , $3,4,5 A$ and 6 .

5. Graphic Presentation of a Complex Stage Model 


\author{
CHAPTER I \\ Statement of the Problem
}

Moral judgment is a psychological construct which was first investigated systematically by Jean Piaget in 1932 . According to Piaget, the term moral judgment refers to an individual's understanding of the rules of justice and fairness by which a society functions. (Piaget, 1965).

One aspect of the research in the area of moral judgment has focused upon a person's reasoning in response to hypothetical moral dilemmas. A moral dilemma is an ambiguous conflict situation which has several possible outcomes. Subjects are presented with the dilemma and asked what is the "correct" course of action to be followed to solve the dilemma. The subject is then required to justify or explain why a particular solution to the moral dilemma was selected. The pattern of responses offered by the individual is then used to determine and evaluate moral judgment level.

In evaluating an individual's responses to moral dilemmas, two competing theoretical perspectives can be identified (Edwards, 1982). Cognitive developmental theories postulate the existence of biologically determined patterns of thought that are influenced by learning and experience (Kohlberg, 1969, 1971). Kohlberg, the most influential of the cognitive developmental theorists, 
suggests a model wherein moral judgment is described as a "typological scheme describing general stages of moral thought that can be defined independently of the specific content of particular moral decisions or actions" (Kohlberg, 1980, p. 20). Further, these patterns of thought, i.e., stages, are internally consistent and occur in invariant sequence. Situational theorists, in contrast, suggest that moral reasoning is the result of the interaction between the situational factors and learning experiences to which the reasoner has been exposed. Simpson (1974), a major proponent of the situational paradigm, suggests that individuals are not predisposed to think in certain ways due to innate biological structures. Rather, it is the content of the particular dilemma which brings culturally learned responses to bear on moral judgments.

In predicting how a subject will respond to moral dilemma situations, the cognitive developmentalist will insist that the individual will produce similar moral reasoning level responses to diverse situations. Specifically, the individual will respond in a manner that is stage typical and consistent across situations. This cognitive-developmental idea of stage unity has been labeled by Kohlberg as the principle of structured wholes and as such forms an underlying tenet of cognitive moral developmental theory. Situational theorists, on the other 
hand, suggest that situational contingencies will be the primary influence on responses to moral dilemmas, wherein situational contingencies are defined as the total array of psychologically meaningful elements impinging upon the individual at any particular time. Thus, responses to diverse moral dilemmas can evoke widely varying patterns of moral reasoning from the individual. Moral judgments are not the product of differentially developed thought processes but rather are the result of situational factors. It is the purpose of this study to empirically investigate the structured whole hypothesis of the cognitive-moral developmental approach. An examination of this hypothesis allows evaluation of the situational and cognitive developmental approaches. If it is found that diverse moral dilemmas evoke widely varying levels of moral reasoning within individuals, i.e., that level of moral reasoning is not consistent across situations as hypothesized by cognitive-developmentalists, then the necessity of considering the effects of situational contingencies or other subject variables on moral reasoning will be underscored.

On the other hand, if individuals demonstrate consistent patterns of moral reasoning across diverse moral dilemmas, an underlying tenet of cognitive developmental theory will be supported. Thus, the intent of this research is to contribute to the empirical validation of 
cognitive developmental theory by testing the hypothesis of structured wholes, i.e., the presence of consistency of moral reasoning by an individual across diverse dilemmas. 
CHAPTER II

Background Theory and Research

The Cognitive Developmental Paradigm

The cognitive developmental paradigm is a major theoretical framework for the conceptualization of moral development. Within this framework, two fundamental concepts can be identified which can be said to define the cognitive developmental approach.

The first of these is that an individual's perceptions of reality are cognitively constructed. The result of these constructions are organized patterns or structures of thought which allow the individual to interpret reality. These structures, which change as the individual develops, represent qualitative rather than quantitative organizations of thought processes.

The second fundamental concept is that developmental stages evolve or change as the result of the reorganization of existing cognitive structures. New stages, which are the result of this reorganization, consist of qualitatively new and different underlying cognitive structures. Developmental change is, therefore, a progression in which earlier cognitive structures are elaborated to accommodate greater complexity in a subject's experience. Three major theorists, Jean Piaget, Lawrence Kohlberg, and James Rest have utilized the cognitive 
developmental approach to explain moral reasoning and its development. This review will now examine the work of these theorists.

\section{Piaget's Simple Two-Stage Model of Moral Reasoning}

Piaget's landmark 1932 work, The Moral Judgment of the Child, first discussed the concept of moral judgment. In this work, Piaget defined moral judgment as an understanding of the rules of justice and fairness by which a society functions (Piaget, 1965). Moral development, in cognitive-developmental terms, refers to the process by which the innate biologically-determined cognitive structures which control and define moral judgment evolve in the individual. For Piaget, the components of cognitive abilities result from an interaction between innate physiologically-based predispositions and experience (Brainerd, 1978).

Piaget hypothesized a two-stage model of moral judgment. According to this model, an individual at different ages will exhibit one of two qualitatively different patterns of thought when dealing with situations that require moral reasoning. The evolution of these thought patterns is due to developmental processes. Piaget suggests that the changes in an individual's reasoning reflect qualitative rather than quantitative changes in cognitive structures. The theory has been 
classified as a disjunctive structural theory since its focus is upon qualitative rather than quantitative changes in cognitive structures.

The two stages of morality as hypothesized by Piaget (1965) are:

1. Heteronomous Morality: The stage of heteronomous morality (ages 6-10) represents the very earliest stage of development wherein the child exhibits consciousness or awareness of rules. This stage of morality, also known as the morality of constraint, results from the interaction of two factors -- cognitive immaturity and unilateral emotional respect for adults. These two factors cause the child to externalize moral rules and to treat these rules as unchangeable absolutes. However, as the child is exposed to reciprocal social interactions and conditions of mutual respect and equality, the second and terminal Piagetian stage of morality develops.

2. Cooperative Morality: The stage of the morality of cooperation represents the highest level of Piagetian moral reasoning (onset at ages 10-14). The individual who exhibits the morality of cooperation views rules as flexible and modifiable. Rules are viewed as a way to express the rights and responsibilities of society's members .

Piaget suggests that all children will ultimately progress from a premoral stage to the stage of the 
morality of cooperation unless development is retarded or impeded by severe social deprivation. Piaget (1965) maintains that under conditions of mutual respect and equality in social interchange, the developing mind cannot help coming to regard the principle of cooperation as "an imminent condition of social relationships."

Kohlberg's Simple Six-Stage Model of Moral Reasoning Kohlberg's cognitive-developmental theory of moral reasoning is an elaboration of Piaget's stage approach to moral development wherein moral development is also described as a series of stages that represent successively differentiated, more complex and more highly integrated patterns of thought. While Piaget was very cautious and nonspecific about the characteristics of moral reasoning stages, Kohlberg has very rigorously defined the concept of stage as it relates to moral judgment (Rest, 1979). Kohlberg notes that moral judgment stages are qualitative descriptors of cognitive processes which exhibit stage unity, i.e., structured wholes; step-by-step invariant sequence and lend themselves error-free, context-independent assessment. Thus, this model is presented as a "typological scheme describing general stages of moral thought that can be defined independently of the specific content of particular moral decisions or actions" (Kohlberg, 1980, p. 20). Kohlberg 
justifies his theory as a typological scheme because "67 percent of most peoples' thinking is at a single stage regardless of the moral dilemma involved" (Kohlberg, 1980, p. 21) and elaborates a theory of morality in which the acquisition of higher levels of reasoning are dependent upon the assimilation and reorganization of lower levels of thought.

Kohlberg hypothesizes three levels and six stages of moral reasoning. In the pre-conventional level, level I, moral value is defined in terms external to the individual. Within the pre-conventional level, Stage 1 defines goodness in terms of the physical consequences of the action. In Stage 2 , an act is characterized as good if it produces what is wanted by the actor from others. At the conventional level, level II, moral value resides in the individual performing good or expected roles. Within the conventional level, Stage 3 represents conformity to the expectations of others, primarily, while stage 4 represents conformity to the rules of established authority. Post-conventional moral development involves goodness as defined independent of the authority invested in persons as groups. Stage 5 recognizes that social contracts are modifiable to meet the needs of social utility. Stage 6 morality is based upon the autonomous functioning of conscience in accordance with the abstract principles of justice, equality, reciprocity and the respect of human 
beings as individuals. A summary characterization of

Kohlberg's model is presented in Table 1 .

Table 1

Lawrence Kohlberg's Classification of Moral Judgment into Levels and Stages of Development

\begin{tabular}{cl} 
Levels & Basis of Moral Judgment \\
\cline { 2 - 2 } & $\begin{array}{l}\text { Moral value resided in } \\
\text { happenal, quasiphysical }\end{array}$ \\
& or in quasiphysical needs \\
& rather than in persons \\
& and standards.
\end{tabular}

I Moral value resides in performing good or right roles, in maintaining the conventional order and the expectancies of others.

$\frac{\text { Stages of Development }}{\text { Stage 1: Obedience and }}$ punishment orientation. Egocentric deference to superior power or prestige, or a troubleavoiding set. Objective responsibility.

Stage 2: Naively egoistic orientation. Right action is that instrumentally satisfying the self's needs and occasionally others'. Awareness of relativism of value to each actor's needs and perspective. Naive egalitarianism and orientation to exchange and reciprocity.

Stage 3: Good-boy orientation. Orientation to approval and to pleasing and helping others. Conformity to stereotypical images of majority or natural role behavior, and judgment by intentions .

Stage 4: Authority and social-order maintaining orientation. Orientation to "doing duty" and to showing respect for authority and maintaining the given 
II I

Moral value resides in conformity by the self to shared or sharable standards, rights, or duties.

social order for its own sake. Regard for earned expectations of others.

Stage 5: Contractual legalistic orientation. Recognition of an arbitrary element or starting point in rules or expectations for the sake of agreement. Duty defined in terms of contract, general avoidance of violation of the will or rights of others, and majority will and welfare.

Stage 6: Conscience or principle orientation. Orientation not only to actually ordained social rules but to principles of choice involving appeal to logical universality and consistency. Orientation to conscience as a directing agent and to mutual respect and trust.

Note. From "Moral and Religious Education and the Public Schools: A Developmental View." In T. Sizer (Ed.), Religion and Public Education (p. 171) by L. Kohlberg, 1967, Boston: Houghton Mifflin.

The model of moral judgment presented by Kohlberg has been described as a direct elaboration of and extrapolation from Piaget's simple two-stage model developed in response to perceived inadequacies in Piaget's model. Kohlberg subdivided, reorganized and redefined the 
Piagetian stages in order that they might be better representations of cognitive developmental theory. Specifically, Kohlberg defined moral reasoning stages such that they met the strict stage criteria of cognitive developmental theory and, in addition, extended the theory from childhood through adulthood.

\section{Rest's Complex Stage Model of Moral Reasoning}

The simple stage models of Piaget and Kohlberg launched initial research efforts in studying moral development. As studies have been completed and a significant body of findings has become available for scrutiny, several serious and consistent problems have been identified. Rest (1979), in an extensive review of the moral development literature points out four inconsistencies which seriously threaten the validity of the simple stage model approach. Two of these identify theoretical issues while the remainder specify primarily methodological problems in the assessment of moral judgment.

a. Theoretical problems in the assessment of moral judgment:

1. The lack of decalage across content domains. Both Piagetian and Kohlbergian theory suggest a subject should exhibit the presence of a certain cognitive skill or moral development stage across all content 
domains. For example, once a subject completes concrete operations, he/she consistently conserves length, mass, weight, etc. Similarly, according to Rest, once a subject has reached a given stage of moral reasoning, this stage should be evidenced in all situations. Rest notes that a) "... constituent counterparts to conservation of mass, weight or transitivity in Piaget's concrete operations" (Rest, 1979, p. 57) have not been identified and b) even Kohlberg's own research suggests that for any given subject, stage scores will be mixed across several moral dilemmas.

2. Subject fluctuation. Rest argues that the acquisition of a given stage of moral reasoning is not an all-or-none matter. According to Rest, subjects' moral development "structures have a probabilistic character, appearing now in evidence, now absent" (Flavell \& Wohlwill, 1969, p. 99). As a result of the "probabilistic nature of moral reasoning structures, it is necessary to have both a quantitative and qualitative measure of such structures. The qualitative measure represents into what stage a subject's reasoning may be classified, while the quantitative measure assesses the degree to which a subject is demonstrating a given stage.

b. Methodological problems in the assessment of moral judgment: 
1. Inconsistencies in stage classification due to test characteristics: Rest points out that several researchers have noted that the specific characteristics of the assessment instrument can significantly affect the manner in which a subject organizes responses. For example, differences in level of response are evident when the relevance of story cues or the degree of familiarity a subject has with the story are manipulated (Rest, 1979). As a result, the classification of a subject's level of moral reasoning may vary due to the test characteristics. 2. Discrepancies in stage scores due to response mode: Several researchers have pointed out that the clinical interview, which is an often used strategy of both Piagetian and Kohlbergian researchers, may seriously underestimate the cognitive skills of the subject. Verbal expressivity may function as an intervening variable, and as a result the reliability of the attained stage score may be questioned.

Rest points out that if different response modes yield discrepant stage estimates, the concept of "having a structure" must be examined more carefully. Rest suggests that it may be possible to "have a structure at different levels." For example, a subject may first have a structure such that it may be made manifest non-verbally; only after additional maturation will the subject be able to 
exhibit the structure verbally. This type of discussion further calls into question the earlier "all-or-none" view of both cognitive and moral development.

Rest has developed a model of moral development which incorporates solutions to the four above-cited anomalies in the moral development literature. Rest begins with Kohlberg's formulation (a summary of Rest's stages are presented in Table 2) but adds two important modifications:

1. Moral development is characterized both qualitatively and quantitatively. Qualitative descriptions define different types, i.e., stage of moral reasoning while quantitative descriptions define the degree to which different structures are present.

2. The presence of a step-by-step developmental sequence is questioned due to the obvious presence of stage mixtures in subjects' responses. Consequently, the presence of a complex stage model is hypothesized wherein a subject may evidence reasoning at several different levels at any given point in time. Figure 1 depicts the kind of non-monotone response patterns that might be assumed to relate ordered response types to an underlying developmental dimension when those response types are part of a disjunctive developmental scale. 


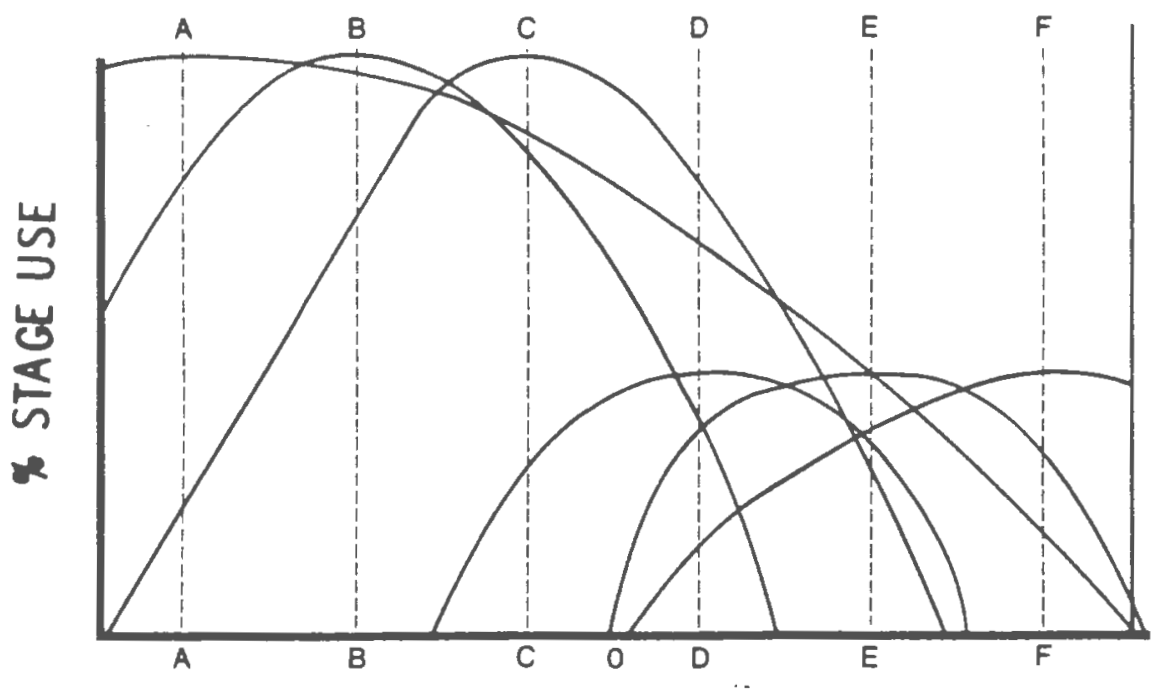

Development

Figure 1. The complex stage model. A disjunctive scale formed by the relative usage of six different stages across development.

Note. From Development in Judging Moral Issues (p. 224) by J.R. Rest, 1969, Minneapolis: University of Minnesota Press.

Table 2

James Rest's Classification of Moral Judgment into Levels and Stages of Development

\begin{tabular}{|c|c|c|c|}
\hline Stage & $\begin{array}{l}\text { Coordination } \\
\text { of Expectations } \\
\text { About Actions } \\
\text { (How Rules are } \\
\text { Known and Shared) }\end{array}$ & $\begin{array}{c}\text { Schemes of } \\
\text { Balancing } \\
\text { Interests (How } \\
\text { Equilibrium is } \\
\text { Achieved) }\end{array}$ & $\begin{array}{l}\text { Central Concept } \\
\text { for Determining } \\
\text { Moral Rights and } \\
\text { Responsibilities }\end{array}$ \\
\hline 1 & $\begin{array}{l}\text { The caretaker } \\
\text { makes known } \\
\text { certain demands }\end{array}$ & $\begin{array}{l}\text { The child does } \\
\text { not share in } \\
\text { making rules. }\end{array}$ & $\begin{array}{l}\text { The morality of } \\
\text { obedience: "Do } \\
\text { what you're }\end{array}$ \\
\hline
\end{tabular}


on the child's behavior.

Although each person is understood to have his own interests, an exchange of favors might be mutually decided.

Through reciprocal role taking, individuals attain a mutual understanding about each other and the on-going pattern of their interactions.

All members of society know what is expected of them through public institutionalized law.

Formal procedures are institutionalized for making laws, which one but understands that obedience will bring freedom from punishment.

If each party sees something to gain in an exchange, then both want to reciprocate.

Friendship relationships establish a stabilized and enduring scheme of cooperation. Each party anticipates the feelings, needs, and wants of the other and acts in the other's welfare.

Unless a societywide system of cooperation is established and stabilized, no individual can really make

plans. Each

person should

follow the law and do his particular job, anticipating that other people will also fulfill their responsibilities.

Law-making procedures are devised so that they reflect the general will of told.

The morality of instrumenta 1 egoism and simple exchange: "Let's make a deal."

The morality of interpersonal concordance: "Be considerate, nice, and kind, and you'll get along with people."

The morality of law and duty to the social order: "Everyone in society is obligated and protected by the law."

The morality of society consensus: "You are obligated by whatever ar- 
anticipates

rational people would accept.
6 the people, at the same time insuring certain basic rights to all. With each person having a say in the decision process, each will see that his interests are maximized while at the same time having a basis for making claims on other people.

A scheme of cooperation that negates or neutralizes all arbitrary distribution of rights and responsibilities is the most equalibrated, for such system is maximizing the simultaneous benefit to each member so that any deviation from these rules would advantage some members at the expense of others. rangements are agreed to by due process procedures."
The morality of non-arbitrary social cooperation: "How rational and impartial people would organize cooperation is moral."

Note. From Development in Judging Moral Issues (pp. $\overline{22-23}$ ) by J.R. Rest, 1979, Minneapolis: University of Minnesota Press.

As Table 2 indicates, Rest's model describes theoretically the assumed understanding at each stage of two factors underlying moral development, i.e., concepts of how expectations about each other's actions are coordi- 
nated, known and shared; and concepts about how an equilibrium or balance of interests of people in a cooperating group is achieved. These two factors determine the central concept for assigning moral rights and responsibility and give logical unity to the various characteristics of people's moral judgments.

Development, as described by the complex stage model, is sequential as well as hierarchical wherein development is described as a continuous rather than discrete process. Within this model, a subject is hypothesized to exhibit a developmental profile rather unitary stage behavior. Further, this profile is hypothesized to be consistently evident across dilemmas.

In a further attempt to deal with the empirical inconsistencies in assessment of moral reasoning due to methodological difficulties, Rest and his associates have developed an objective measure of cognitive moral judgment which offers several advantages over Kohlberg's methodology including the minimization of variance in stage scores due to verbal expressivity; objective scoring resulting in the minimization of scorer bias; the calculation of a continuous (vs. discrete) index (i.e., the P-score) to represent a subject's moral judgment level (Rest, 1974).

Rest's instrument, the Defining Issues Test (DIT), (see Appendix B) requires that the subject evaluate 
various issues representing thinking at the six levels of moral reasoning. As such, the DIT is a recognition rather than a production task. While Kohlberg's procedure requires the examiner to classify a subject's responses according to a scoring guide, the DIT requires the subject to rate his own responses. As a result, objective machine scoring is possible. While it is not appropriate to use the DIT to predict scores on Kohlberg's test, the DIT is a useful research tool to investigate questions about cognitive moral development.

\section{The Concept of Stage in Moral Development Theory}

The work of Piaget, Kohlberg and Rest present a theory of moral judgment in which the concept of stage plays a vital role. According to Piaget, the concept of stage "... refers to a mode pattern or constellation of behavior (or dispositions toward behavior) that seem to characterize some definable point in the child's life" (Flavell \& Wohlwill, 1969, p. 91). Stages within this paradigm satisfy a set of well-defined criteria. These criteria for cognitive development are defined in Piaget's work The General Problem of the Psycho-Biological Development of the Child (Piaget, 1965).

1. Qualitative descriptors:

Stages imply distinct or qualitative differences in children's modes of thinking or of solving the same problem at different stages. 
2. Step-by-step invariant sequence:

These different modes of thought form an invariant sequence, order or succession in individual development. While cultural factors may speed up, slow down, or stop development, they do not change its sequence.

3. Stage unity:

Each of these different and sequential modes of thought forms a "structured whole." A given stage-response on a task does not just represent a specific response determined by knowledge and familiarity with that task of tasks similar to it; rather it represents an underlying thought organization.

4. Hierarchical integration:

Cognitive stages are hierarchical integrations. Stages form an order of increasingly differentiated and integrated structures to fulfill a common function.

These four criteria define the cornerstones upon which the framework of cognitive moral development theory is laid. Any attempt at empirical validation of cognitive moral developmental theory must first establish the relationship and validity of these four underlying assumptions as they apply to moral reasoning.

Kohlberg's model of moral reasoning interprets three of these four criteria -- qualitative descriptors, step-by-step invariant sequence, stage unity -- quite rigorously. 
1. Qualitative descriptors: Kohlberg holds that stages describe qualitative states. But in addition, he argues that it is inappropriate to quantitatively specify "amounts" of a stage. Kohlberg stages, "Structural theory does not treat any change in structural competence unless the change is evident in a qualitatively new pattern of response" (Kohlberg 1973, p. 181).

2. Stage unity: For Kohlberg, the concept of stage unity or structured whole implies "conservation and other logical operations should appear as a logical and empirically related cluster of responses in development." (Kohlberg, 1969, p. 353) Thus, "... individuals should be consistently at a stage unless they are in transition to the next stage ..." (Kohlberg, 1969, p. 353). This allows only that a subject will exhibit a single stage or a stage plus one in moral reasoning.

A graphic presentation of these aspects of simple stage theory are presented in Figure 2. From Figure 2 the following characteristics of the simple stage model are in evidence:

a. Each stage has a turn at predominance in use over other stages and each stage peaks at 1008 usage. b. The only stage mixture that can occur is between adjacent stages.

c. Stages are evenly spaced across development. 


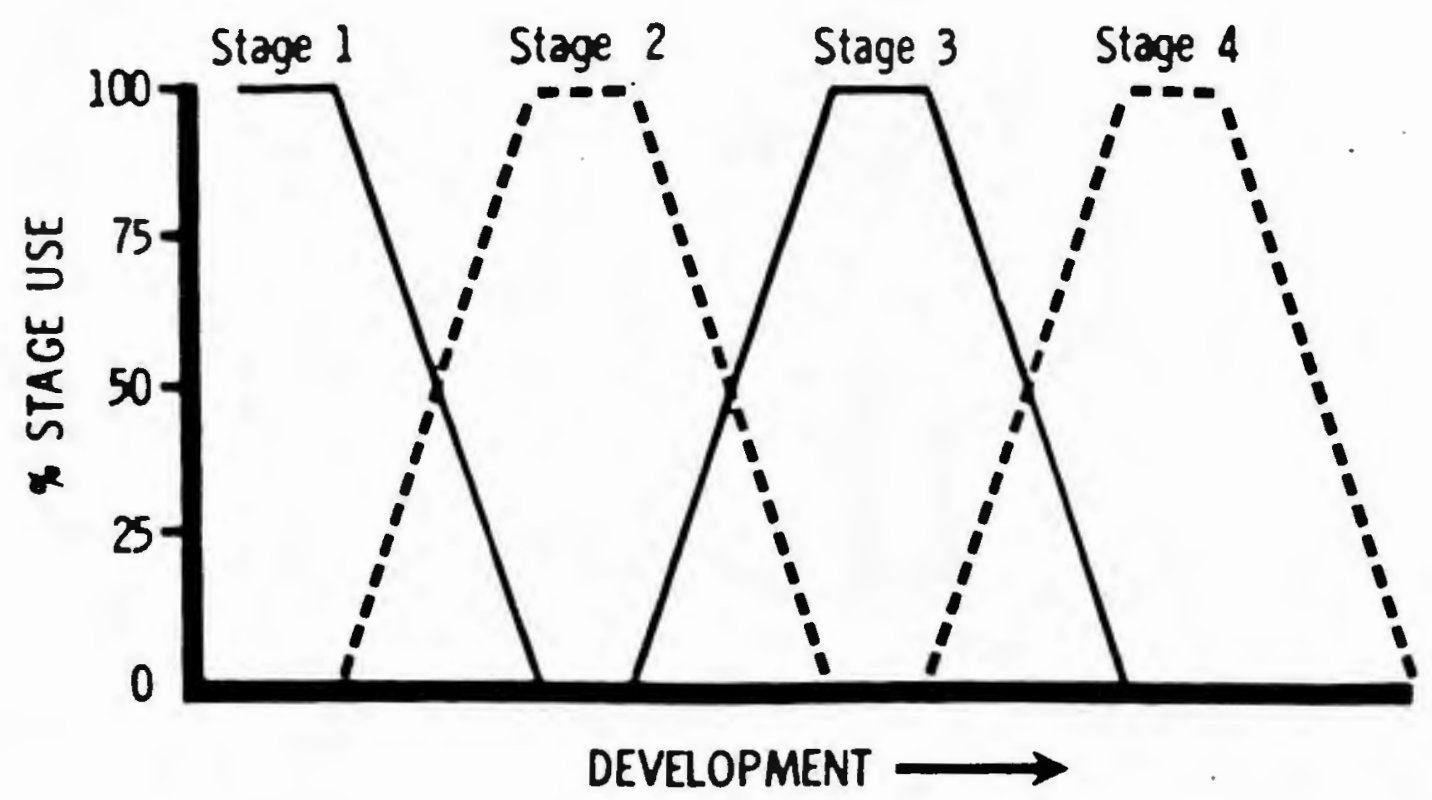

Figure 2. Graphic presentation of the simple stage model. Note. From Development in Judging Moral Issues (p. 52) by J.R. Rest, 1979, Minneapolis: University of Minnesota Press.

\section{Step-by-step invariant sequence: Kohlberg} states "Stage theory holds that every single individual, studied longitudinally, should only move one step at a time through the stage sequence and always in the same order (Kohlberg et al.. 1976). Thus, stage mixture or regression is specifically forbidden by Kohlberg.

Rest, in contrast to the rigorous application of Piagetian stage criteria suggests some modification to 
these criteria which allows for a better empirical fit of the theory with extant data. Specifically, Rest suggests the following:

1. The idea that the existence of a stage is an "all or nothing" affair is incorrect. Developmental stages must be characterized both qualitatively and quantitatively. Rest states "... the question of developmental assessment should not be 'What stage is a person in?' but rather 'To what extent does a person manifest the various types of organizations, (i.e., stages) of thinking" (Rest, 1976, p. 35).

2. The notion of step-by-step invariant sequence is not supported by the current research. Consequently, stage movement may be more appropriately thought of as quantitative organizational advance. That is the amount of various stages present in subjects' responses change in a complimentary fashion. For example, a subject may move to "advanced" levels of Stage 3, "moderate" levels of Stage 4 and to "primary" levels of Stage 5. (Rest, 1979, p. 65$)$.

Figure 5 presents a graphic representation of Rest's conceptualization of developmental change. In this conceptualization a developmental order is evident in which the subject's thinking creates a profile. 


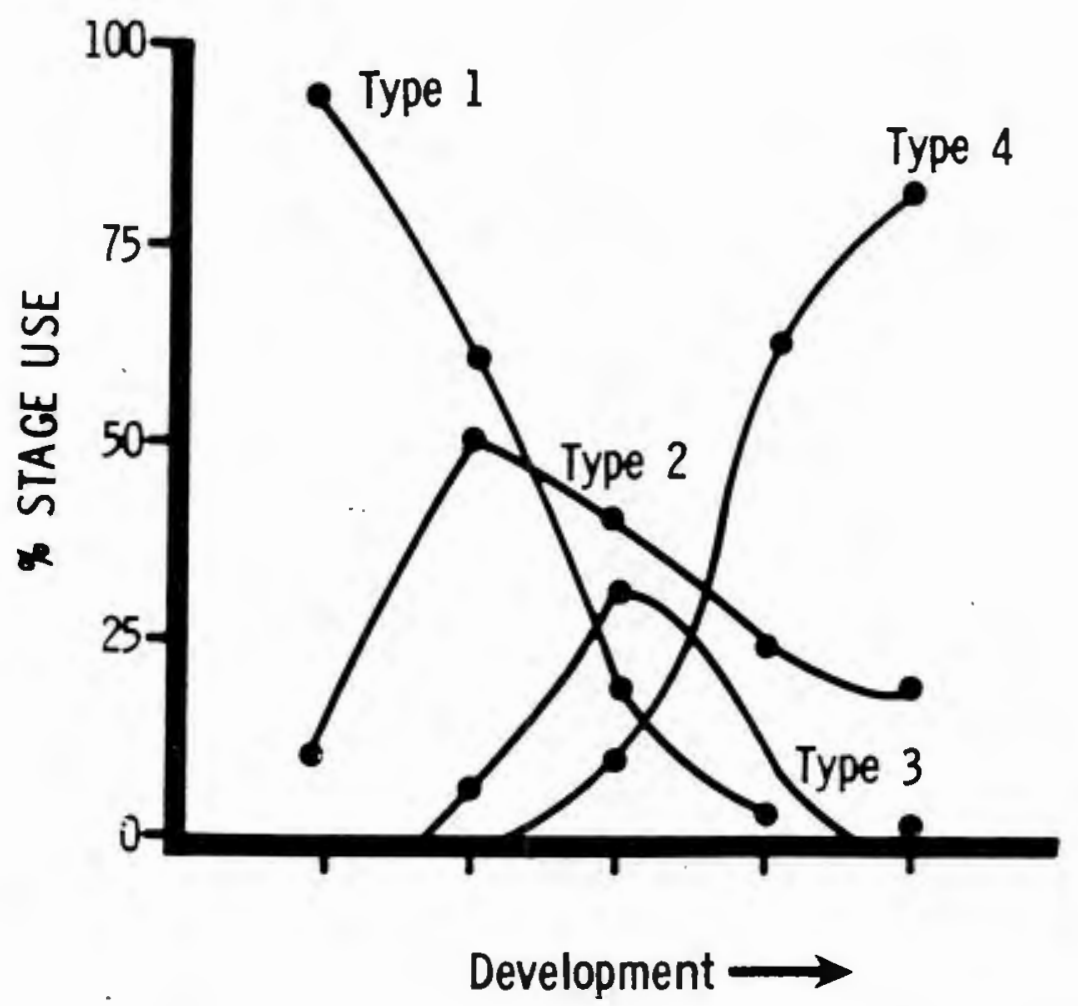

Figure 5. Graphic presentation of a complex stage model. Note. From Development in Judging Moral Issues (p. 66) by J.R. Rest, 1979, Minneapolis: University of Minnesota Press.

of the four characteristics of cognitive developmental theory discussed, the criterion of stage unity or structured whole is considered by both Piaget and Kohlberg to be the central criterion of structural stages (Piaget, 1960; Kohlberg, 1984). For Kohlberg structured wholeness refers to the

... conception of an underlying thought organization that determines responses to tasks that are not manifestly similar. The general 
implication of this conception is that individuals' thinking will be manifested at a single dominant stage when observed across instances of varying content, though the presence or usage of the stage adjacent to the dominant stage may also be expected.

\section{(Colby, Gibbs \&}

Liberman, 1983)

For Rest, this concept implies that subjects will demonstrate a consistent pattern of stage level responses across dilemmas of varying content.

As noted, the concept of stage unity is a central criterion upon which cognitive moral development theory is based. As such, validation of moral development theory is contingent upon the empirical validation of this concept.

\section{The Situational Paradigm}

While cognitive development theories of moral judgment represent a much used paradigm in the field, proponents of social psychology offer alternative explanations for behavior and reasoning in and about moral dilemmas. The social psychologist suggests that subjects are the products of their environment. Behaviors and consequently reasoning vary according to the environmental pressures impinging upon the subject.

The work of Elizabeth Simpson (1974) states succinctly the position of proponents of such situational theorists. Simpson suggests that moral developmental levels are determined by a combination of environmental and 
cultural influences. She suggests that observed differences in subjects' moral judgments are not the product of differentially developed thought processes but rather the effect of situational factors. For her, it is the content of the particular situation, i.e., dilemma, which brings culturally learned responses to bear on moral judgments.

Simpson's work is a logical extension and culmination of the work of several early researchers who examined variables hypothesized to have an effect upon moral judgment and/or behavior. Medinnus (1959) and Magowan and Lee (1970) found that familiarity with the situation within which the moral dilemma is posed exerts a direct influence on moral judgments with more "mature" judgments elicited in familiar situations. Hartshorne and May (1928), in a series of classic studies examining cheating behaviors, found that honesty and deceit were not unified character traits but rather situation specific, i.e., most children will deceive in certain situations but not in others. A third line of research within the situational paradigm has examined the effect of perceived consequences upon moral reasoning or behavior. Vitro (1969) found that when students believed a test was important and would affect their course grade; they were more likely to cheat than when they believed the test was unimportant. In a similar vein, Plummer (1983) attempted to examine systematically the effect of situational variables on moral 
reasoning. He found that the severity of the consequences experienced by the actor in a moral dilemma affected the level of moral reasoning offered by subjects. Sobesky (1983), in a study assessing the interaction between moral development level of subjects and negative consequences, also found that the consequences for the actor in a moral dilemma influenced both moral judgment and moral thought.

\section{Empirical Findings}

In reviewing the literature that addresses the concept of stage unity, one can identify very few studies which assess the presence of or the degree of consistency in subjects' responses.

In moral judgment research using the Piagetian stage dimensions of immanent justice, objective responsibility, retributive justice and expiatory punishment, Hoffman (1970) in an extensive review of the literature concludes that there is no evidence for consistency across various concepts. In contrast Johnson (1972) reports consistency across these dimensions. Neither the work of Hoffman nor Johnson specifically addresses the overall presence of stage consistency in subjects' responses.

In moral judgment research based on Kohlbergian stages, the issue of stage consistency appears to be related to the scoring system employed to stage type subjects' responses. In Kohlberg's earlier scoring 
subjects' responses. In Kohlberg's earlier scoring system, the evidence of stage mixture appears clear. Kohlberg (1969) reported that 478 of a subject's responses were in the predominant stage. Employing a scoring system developed in 1978, Colby et al. (1979) reported that 678 of the responses were in a subject's predominant stage.

Several researchers have also suggested that the specific type of testing materials, the specific instructions or procedures used may significantly affect the way in which subjects organize their responses.

Flavell and Wohlwill (1969), reviewing the literature examining test characteristics, conclude that "the stimulus materials and their familiarity, the manner of presentation of the relevant information and the amount of irrelevant information" (p. 99) presented can significantly affect subjects' responses.

In the moral judgment literature, several investigators have examined the effect of test characteristics on the two-stage model of Piaget. These studies have suggested that many kinds of test characteristics can affect the type of reasoning offered by subjects in response to piagetian dilemmas. These studies are summarized in Table 3. 
Table 3

Sumary of Studies Investigating the Effects of Test Characteristics on Piagetian Dilemmas

\begin{tabular}{|c|c|c|}
\hline Study and Sample & $\begin{array}{l}\text { Characteristics } \\
\text { of Treatment }\end{array}$ & $\begin{array}{l}\text { Change of } \\
\text { Exp. Group }\end{array}$ \\
\hline Baldwin (1970) & $\begin{array}{l}\text { Comparison of two } \\
\text { Piagetian concepts }\end{array}$ & $\begin{array}{l}\text { Significant dif- } \\
\text { ferences in onset } \\
\text { of acquisition }\end{array}$ \\
\hline $\begin{array}{l}\text { Bug \& Cross } \\
(1975)\end{array}$ & $\begin{array}{l}\text { Single story vs. } \\
\text { story pairs }\end{array}$ & $\begin{array}{l}\text { Significant in- } \\
\text { crease of level } \\
\text { of moral reasoning }\end{array}$ \\
\hline $\begin{array}{l}\text { Beindt \& Beindt } \\
(1975)\end{array}$ & $\begin{array}{l}\text { Variation in } \\
\text { story consequence }\end{array}$ & $\begin{array}{l}\text { Significant con- } \\
\text { sequence effect }\end{array}$ \\
\hline $\begin{array}{l}\text { Buchanan \& } \\
\text { Thompson (1973) }\end{array}$ & $\begin{array}{l}\text { Paired vs single } \\
\text { presentation of } \\
\text { Piagetian prin- } \\
\text { ciples }\end{array}$ & $\begin{array}{l}\text { Significant in- } \\
\text { crease of level } \\
\text { of reasoning with } \\
\text { single presenta- } \\
\text { tion }\end{array}$ \\
\hline $\begin{array}{l}\text { Chandler et al. } \\
(1973)\end{array}$ & $\begin{array}{l}\text { Verbal vs. visual } \\
\text { presentation }\end{array}$ & $\begin{array}{l}\text { Significant in- } \\
\text { crease with visual } \\
\text { presentation }\end{array}$ \\
\hline $\begin{array}{l}\text { Collins et al. } \\
(1974)\end{array}$ & $\begin{array}{l}\text { Age used as a } \\
\text { variable }\end{array}$ & $\begin{array}{l}\text { Significant age } \\
\text { effect }\end{array}$ \\
\hline $\begin{array}{l}\text { Irwin \& Moore } \\
\quad(1971)\end{array}$ & $\begin{array}{l}\text { Story actors } \\
\text { selected to match } \\
\text { children }\end{array}$ & $\begin{array}{l}\text { Significant in- } \\
\text { crease of level } \\
\text { of moral reasoning }\end{array}$ \\
\hline $\begin{array}{l}\text { Shang \& Voydanoff } \\
\text { (1973) }\end{array}$ & $\begin{array}{l}\text { Repetition of } \\
\text { story }\end{array}$ & $\begin{array}{l}\text { Significant in- } \\
\text { crease with repe- } \\
\text { tition }\end{array}$ \\
\hline
\end{tabular}

Using the Kohlbergian paradigm, Liebermann (1971) reported that the dilemmas included in the 1958 version elicited differential responses from subjects. Leming (1975) reports that a set of "practical" moral dilemmas elicited different stage responses than Kohlberg's set. 
Crockenberg and Nicolayev (1977) also found discrepancies between Kohlberg's Form A and Form B. Colby (1979), however, reports a correlation of .84 between forms and $85 \%$ agreement within a half stage. McGeorge (1974) also reports significant variation between responses of forty 12-year old boys and 23 university students. Both of McGeorge's studies may be criticized because of extremely small sample size. In a similar vein, Plummer (1982) also found stage mixture in a sample of 70 college sophomores. In examining the literature employing Rest's complex stage model no study could be identified which specifically addressed the question of consistency of subjects' responses across dilemmas.

In an extension of his 1982 work, Plummer (1983) examined systematically the effect of situational variables on moral reasoning. He found that the severity of the consequences experienced by the actor in the moral dilemma affected the level.

Research Question

The issue examined in this research is the validity of the cognitive developmental assumption of stage unity, i.e., "structured wholes." Cognitive moral developmental theory posits that a subject will demonstrate a consistent level of moral reasoning across dilemmas of varying content. The simple stage theorist holds that a subject 
will exhibit a single stage or a single stage plus one (if the subject is in transition) in responding to moral dilemmas. Neither stage mixture nor stage regression is permitted. Similarly, the complex stage theorist will maintain that while stage mixture is likely, the general pattern (percentages of stages exhibited) of responses will be consistent across dilemmas. That is, while a single dilemma is likely to elicit more than one level of reasoning and a subject's moral reasoning is most accurately described using both quantitative and qualitative descriptors, the percentages of stage usage should remain generally consistent across dilemmas of varying story content. Thus, the question addressed by this research is: do subjects exhibit a consistent level of moral reasoning or pattern of levels of moral reasoning when presented with dilemmas of diverse story content? 
CHAPTER III

Method

\section{Subjects}

The 300 students who served as subjects for this study were volunteers from an introductory level psychology course at a mid-sized state university. The students enrolled in this course generally are undergraduates who range in age from 18 to 24. Early in the semester, prior to any lectures on cognitive or moral development theory, volunteers were solicited. All subjects who participated in the study were awarded extra points on their final course grade.

This study was reviewed and approved by the Institutional Review Board at the University of Rhode Island. (See Appendix A.) Informed consent of subjects was obtained prior to subjects' participation and subjects were de-briefed at the conclusion of this project.

\section{Instruments}

Defining Issues Test (DIT). The DIT, designed by Rest, (1979) (see Appendix B) is a measure of cognitive-moral development which"... attempts to assess what people see as crucial moral issues in a situation by presenting subjects with a moral dilemma and a list of 
definitions of the major issues involved" (Rest, 1976, p. 89). This instrument consists of six moral dilemma situations. Each situation is qualitatively different and involves a variety of protagonists. Following each dilemma are twelve statements which characterize various issues that might affect the respondant's decision about the course of action to be followed. These twelve issues reflect reasoning at moral reasoning levels $2,3,4,5 \mathrm{~A}$, $5 B, 6$. There are no stage 1 items because the reading level and general maturity level required to complete the instrument are so high that finding stage 1 subjects is unlikely. Similarly, there are few stage 2 items because most subjects are assumed to reason beyond this stage. The stages in which subjects' thinking is expected to focus are stages $3,4,5 \mathrm{~A}, 5 \mathrm{~B}$ and 6 , and as a result, the items representing reasoning at these stages are included. Stages $5 \mathrm{~A}$ and $5 \mathrm{~B}$ represent different facets of stage 5 reasoning frequently employed by subjects when responding to the moral dilemmas comprising the DIT.

In responding to the DIT, subjects are first required to decide the course of action to be followed in resolving the moral dilemma. They are then required to rate each of the twelve statements representing moral reasoning at levels $2,3,4,5 \mathrm{~A}, 5 \mathrm{~B}$, and 6 from "great importance" to "no importance" in respect to the decision made to resolve the moral dilemma. Finally subjects identify and rank the 
four most important issues in respect to the decision made to resolve the dilemma.

Each of the four issues identified and ranked in importance in respect to the decision made to resolve the dilemma is weighted as follows: first choice, 4 points; second choice, 3 points; third choice, 2 points; fourth choice, 1 point. The stage scores for moral reasoning levels $2,3,45 \mathrm{~A}, 5 \mathrm{~B}$ and 6 are then calculated by summing the scores for the four issues identified most important by moral reasoning level across all six dilemmas. The P-score, which represents reasoning at the principled morality levels, represent the stage score sum for levels $5 \mathrm{~A}, 5 \mathrm{~B}$ and 6 . The 8 P-score is derived by dividing the P-score by the total number of possible points on the entire test.

In order to establish the validity of this instrument Rest provides seven types of logical and empirical evidence:

1. Criterion group validity. Criterion group validity refers to the ability of an instrument to provide differential scores for groups of subjects who logically would be expected to have different scores. In order to establish the criterion group validity of the DIT, Rest (1976) collected data from 50 studies on 5,714 subjects in 136 different samples. Examination of these data suggest that subjects with differing educational levels show 
significantly discriminant DIT scores. Rest contends that subjects' DIT scores should be positively correlated with educational level since both indices tap cognitive development in general. Thus, if subjects at different educational levels evidence differential DIT performance, evidence for criterion group validity is provided. These data are summarized in Table 4 .

Table 4

Student Group Averages on DIT P-Scores

Group

Junior high

Senior high

College

Graduate

$\underline{\mathrm{n}}$

2,479

183
Average $\mathrm{P}$ \%

21.9

31.8

$42 \cdot 3$

53.3

2. Convergent-divergent validity. In order to establish the validity of an instrument to assess a given construct, subjects' performance on the instrument in question is correlated on other accepted measures of that construct. Such a correlation should be positive. Conversely, if the instrument in question is correlated with other measures of other, non-related constructs a small or negative correlation should result. In order to establish the convergent-divergent validity of the DIT, Rest (1979) presents several studies which correlated the 
DIT with performance on Kohlbergian tests of moral

judgment. These studies, which are summarized in Table 5 , suggest that the DIT significantly correlates with both Kohlberg's and Gibb's measures of moral reasoning.

Table 5

Correlations of DIT P-Score with Kohlbergian Tests of Moral Judgment

\begin{tabular}{ccccc}
\hline Sample & $\underline{\mathrm{n}}$ & \multicolumn{1}{c}{ Measure } & $\underline{r}$ \\
1 & 45 & Kohlberg's 1976 Scoring & .78 \\
2 & 91 & Kohlberg's 1972 Issue Scoring & .75 \\
3 & 41 & Gibbs' Scales & .70 \\
4 & 47 & Kohlberg's 1958 Scoring & .68 \\
5 & 213 & Kohlberg's 1972 Scoring & .68 \\
\hline
\end{tabular}

3. Longitudinal validity. With any construct that postulates a natural developmental course, it is imperative to assess subjects across the variable of time. In order to establish the longitudinal validity of the DIT, Rest provides data which offers at least weak support for the longitudinal validity of the DIT. These data, which are sumarized in Table 6 , indicate that in five of the six studies cited by Rest (1979), mean P-score increased, suggesting the presence of a natural developmental course across the variable of time. 
Table 6

Two-Year Changes in DIT P-scores

$\begin{array}{crcr}\text { Group } & \underline{\mathrm{n}} & \frac{2}{\text { Time }} \mathrm{l} & \frac{\text { Time }}{2} \\ 1 & 15 & 32.7 & 48.2 \\ 2 & 23 & 36.0 & 43.9 \\ 3 & 11 & 42.0 & 39.2 \\ 4 & 18 & 29.5 & 36.8 \\ 5 & 8 & 36.9 & 42.3 \\ 6 & 10 & 25.0 & 34.4\end{array}$

4. Validation through experimental enhancement studies. Rest suggests that the validity of the DIT can be demonstrated by identifying experiences or learning conditions that are especially enhancing to the construct of moral development. Subjects are then exposed to those experiences and "pre-post" gains on the instrument are assessed. While several intervention studies have been completed, Rest identifies a study completed by Balkcum (1979) as offering validation through enhancement. Subjects were undergraduates aged 17 to 44 in a two-year general arts and sciences college. Seventy-three had enrolled in an ethics course and 28 had enrolled in a logic course. The DIT was administered before and after the course. As a test of logic the Cornell Critical Thinking Test (CCTT) was used. The ethics course gave students a concentrated experience in solving complex 
moral dilemmas, while the logic course was aimed at developing rigorous and systematic thinking. Table 7 presents group means of the pre and post tests for both groups on both measures.

Table 7

Means on Pre and Post Test of the DIT and CCTT in the Ethics and Logic Classes

\begin{tabular}{lccccccc}
\hline & \multicolumn{3}{c}{ DIT } & & \multicolumn{3}{c}{ CCTT } \\
Ethics class & $4 \frac{\text { Pre }}{1.6}$ & $\frac{\text { POSt }}{46.5}$ & $2.06^{*}$ & $4 \frac{t}{3.8}$ & $\frac{\text { Post }}{44.7}$ & $1 . \overline{8} 8$ \\
Logic class & 40.1 & 46.5 & 1.12 & 44.8 & 47.5 & $2.17 *$ \\
\hline
\end{tabular}

${ }^{*} \underline{p}<.05$.

The data indicate that the ethics class went up on the DIT but not on the logic test, whereas the logic class went up on the logic test but not on the DIT.

6. Psychometric reliability. In order for an instrument to be a valid instrument it must have demonstrated reliability. Table 8 presents the data offered by Davison (1979) to establish the test-retest reliability of the DIT. 
Table 8

Test-Retest Correlation Coefficients of the P-Scores on the DIT

$\underline{\mathrm{n}} \quad \underline{\text {-Score }} \underline{\text { Time Interval }} \underline{\mathrm{r}}$

Sample 1

Test

Retest

123

40.78

5 mo.

.82

Sample 2

Test

Retest

44.93

Retest

Sample 3

Test

Retest

33

36.48

$1 \mathrm{mo.}$

.81

35.78

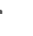

Davison (1979) also reports the following range of test-retest reliabilities for the DIT stage scores $(\underline{N}=$ $19-123)$.

$$
\begin{aligned}
& \text { Stage } 2, r=.30-.70 ; \text { Stage } 3, r=.32-.52 ; \\
& \text { Stage } 4, r=.27-.74 ; \text { Stage } 5 \mathrm{~A}, r=.53-.59 ; \\
& \text { Stage } 5 \mathrm{~B}, \mathrm{r}=.39-.58 ; \text { Stage } 6, r=.26-.50
\end{aligned}
$$

It is important to note that the test-retest reliabilities of the stage scores vary considerably. This lack of consistency may be due in part to the small sample sizes or may reflect an underlying lack of stage unity or suggest lack of internal consistency in the stage instrument itself. 


\section{Procedure}

This study was conducted early in the semester prior to any lectures on cognitive or moral development in order that subjects' performance on the Defining Issues Test might not be affected by exposure to the theories of Jean Piaget or Lawrence Kohlberg.

The 300 subjects were administered the Defining Issues Test with the standard instructions supplied in the test manual. All subjects were administered the DIT simultaneously; monitors were present during the test administration. Subjects were allowed an unlimited time to complete the DIT. No subject took longer than 70 minutes to complete the instrument.

A combination of machine and hand-scoring was used to score the DIT protocols. Percent P-scores and P-scores were obtained through machine scoring of the DIT protocols. Issue ranking totals were obtained through hand scoring of the DIT protocols by the principal investigator. 
CHAPTER IV

Results

In order to assess the relationship between the variables of dilemma and moral development level, the frequencies for each level of moral reasoning cited as most important in each of the six dilemmas in deciding the course of action to be followed for the 300 students administered the Defining Issues Test were calculated. These frequencies are presented in Table 9.

Table 9

Frequency of Level of Reasoning Cited as Most Important

\section{Defining}

Issues Test

Di lemma

1

2

3

4

5

6

Total

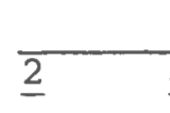

$25 \quad 104$

13

31

0

52

23

18

141

47

21

54

89

23

53

28

86

87

1441

Row totals do not sum to 300 since some subjects selected meaningless but complex-sounding items, i.e., "M" 
items, as the most important issue in deciding the course of action to be followed in resolving the dilemma. Thus the total 220 in row 1 indicates that 80 subjects selected the "M" item on Dilemma 1 .

The zero entries in Table 9 indicate that reasoning at a given level was not present for a given dilemma. Thus the zero in column 1 indicates that there were no level 2 statements for dilemma four.

A $6 \times 6$ chi-square analysis was performed on these frequencies to analyze the relationship between dilemma and moral development level of responses (Stages $2,3,4$, $5 \mathrm{~A}, 5 \mathrm{~B}$, and 6 ) on the Defining Issues Test. Since the obtained $y^{2}=25(N=300)=478.1$, $\underline{p}<.01$, non-independence between the variables of dilemma and moral reasoning level is indicated.

In order to evaluate independence within a stage level across dilemmas, further tests were performed. Thus the initial $6 \times 6$ contingency table was divided into six $1 \times 6$ tables, one for each of the moral reasoning levels. The obtained $y^{2}$ s are reported in Table 10 . 
Table 10

Chi-Square Goodness-of-Fit Test for DIT Dilemma's X Level of Reasoning

Level of

Reasoning

2

3

4

$5 \mathrm{~A}$

$5 \mathrm{~B}$

6

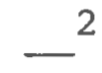

d

$62 \cdot 0^{*}$

$78 \cdot 3 *$

$129.6 *$

5

5

5

5

${ }^{*} \underline{\underline{p}} \leq .001$

Since significant differences were found between the expected and observed frequencies for all 6 levels of moral reasoning. The presence of a relationship between dilema and moral reasoning level is supported.

Because some stages were unrepresented or unequally represented in some dilemmas, from the original 6 DIT moral dilemmas, the 4 dilemmas which included issues representing moral reasoning at levels $2,3,4,5 \mathrm{~A}$ and 6 were identified. There were the Heinz, Student, Webster and Doctor dilemmas. Issue rankings for these dilemmas were scored as follows: great importance, 5; much importance, 4; some importance, 3; little importance, 2; no importance, I. The issue rankings for the Heinz, Student, Webster and Doctor dilemmas summed for the moral 
reasoning levels $2,3,4,5 \mathrm{~A}$ and 6 are reported in Table 11. Means and standard deviations for these summed issue rankings are reported in Table 12 .

Table 11

Sum of Weighted Issue Rankings on the Heinz, Student, Webster, and Doctor Dilemmas $(\mathrm{N}=255)$

Level of Reasoning

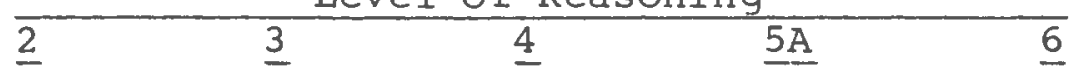

$\begin{array}{llllll}\text { Heinz } & 804 & 840 & 686 & 690 & 754 \\ \text { Student } & 737 & 793 & 830 & 748 & 743 \\ \text { Webster } & 874 & 706 & 860 & 658 & 579 \\ \text { Doctor } & 476 & 799 & 833 & 874 & 770\end{array}$

Table 12

Means (M) and Standard Deviations (SD) of Weighted Issue Rankings for the Heinz, Student, Webster and Doctor Dilemmas $(\mathrm{N}=255)$

Level of Reasoning

$\frac{2}{M \quad \underline{S}} \quad \frac{3}{M} \underline{S D} \quad \frac{4}{M} \underline{S} \quad \frac{5}{M} \underline{S} \bar{M} \quad \frac{6}{M}$

Heinz $\quad 3.74 \quad 1.75 \quad 3.91 \quad 1.22 \quad 3.191 .01 \quad 3.21 \quad 1.10 \quad 3.51 \quad 1.16$

Student $3.43 \quad 0.75 \quad 3.68 \quad 1.09 \quad 3.86 \quad 1.11 \quad 3.48 \quad 1.04 \quad 3.46 \quad 1.1$

Webster $4.07 \quad 0.57 \quad 3.28 \quad 1.17 \quad 4.00 \quad 1.00 \quad 3.06 \quad 1.12 \quad 2.69 \quad 1.13$

Doctor $2.21 \quad 1.14 \quad 3.72 \quad 1.27 \quad 3.87 \quad 1.16 \quad 4.07 \quad 1.03 \quad 3.58 \quad 1.05$ 
Hartley's F-maximum test performed to test the assumption of homogeneity of variance among the 20 treatment conditions was not significant $\left(\underline{F}_{\max }(20,214)\right.$ $=.89, \mathrm{p}>.05)$. These data were then analyzed in a $4 \times 5$ analysis of variance with repeated measures on both factors. The analysis of variance for repeated measures on the issue rankings for the Heinz, student, Webster and Doctor dilemma across moral reasoning levels $2,3,4,5 \mathrm{~A}$ and 6 indicated a significant dilemma effect, $\underline{F}(3,642)=$ 31.5, $\mathrm{p}<.001$, a significant moral reasoning level effect, $\underline{F}(4,856)=81.5, \underline{p}<.001$, and a significant dilemma by moral reasoning level interaction. $\underline{F}(12,2568)$ $=33.5, \underline{p}<.001$, which indicates that dilemmas differentially elicited different levels of moral reasoning from subjects. The analysis of variance summary is presented in Table 13.

Table 13

Summary of $5 \times 4$ Analysis of Variance of Issue Rankings for 5 Dilemmas and 6 Levels of Moral Reasoning ( $N=255)$

\begin{tabular}{|c|c|c|c|c|}
\hline Source & $\underline{S S}$ & $\mathrm{df}$ & MS & $\underline{F}$ \\
\hline $\begin{array}{l}\text { Subjects } \\
\text { within groups }\end{array}$ & 212.0 & 214 & & \\
\hline $\begin{array}{l}\text { Dilemma (D) } \\
\text { Level (L) }\end{array}$ & $\begin{array}{l}154.0 \\
326.0\end{array}$ & $\begin{array}{l}3 \\
4\end{array}$ & $\begin{array}{l}51.33 \\
81.50\end{array}$ & $\begin{array}{l}31.5 * \\
39.6 *\end{array}$ \\
\hline $\mathrm{D} \times \mathrm{L}$ & 1113.0 & 12 & 92.75 & $33 \cdot 5 *$ \\
\hline $\begin{array}{l}\text { Error-D } \\
\text { Error-L } \\
\text { Error-D x L }\end{array}$ & $\begin{array}{l}1049.2 \\
1726.0 \\
7118.1\end{array}$ & $\begin{array}{r}642 \\
856 \\
2568\end{array}$ & $\begin{array}{l}1.62 \\
2.06 \\
2.77\end{array}$ & \\
\hline Total & 11738.3 & & & \\
\hline
\end{tabular}

$\star \underline{p}<.001$. 
A Tukey (A) procedure test for multiple comparisons applied to the issue rankings, totals associated with the levels of moral reasoning reveals that:

1. the Doctor dilemma elicited significantly less Level 2 reasoning than the student, Heinz or Webster dilemma $(\underline{p}<.05)$.

2. the student dilemma elicited significantly les Level 2 reasoning than did the Webster dilemma $(\underline{p}<.05)$.

3. the Heinz dilemma elicited significantly less Level 4 reasoning than did the Student, Heinz or Webster dilemmas $(\underline{p}<.05)$.

4. the Webster dilemma elicited significantly less Level 5 reasoning than did the Doctor Dilemma $(\underline{p}<.05)$

5. the Heinz dilemma elicited significantly less Level 5 reasoning than did the Doctor dilemma $(\underline{p}<.05)$.

6. the Webster dilemma elicited significantly less Level 6 reasoning than did the Heinz, student and Doctor dilemma $(\underline{\underline{p}}<.05)$.

7. that there were no significant differences in ability to elicit Level 3 reasoning among the Heinz, Student, Webster and Doctor dilemmas $(\underline{p}>.05)$. 
Tukey (A) procedure for multiple comparisons applied to the issue ranking totals associated with the four dilemmas reveals that:

1. the Heinz dilemma elicited significantly more Level 3 reasoning than it did Level 4 or Level 5 reasoning .

2. there were no significant differences in level of reasoning elicited on the student dilemma.

3. the Webster dilemma elicited significantly less Level 5 and Level 6 reasoning than it did Level 2, 3 or 4 reasoning; significantly more Level 4 and Level 2 reasoning than Level 3 reasoning, significantly more Level 2 reasoning than Level 3, 45 or 6 reasoning.

4. the Doctor dilemma elicited significantly more Level 5 reasoning than Level 2, 3, 4 or 6 level reasoning •

The Tukey (A) tables are presented in Appendix D. Performance curves for these data are presented in Figures 3 and 4. As can be seen in Figures 3 and 4 , the four dilemmas evidence significantly different profiles. That is, each of the dilemmas elicited significantly different levels of moral reasoning. The Doctor dilemma elicited significantly more level 5 reasoning and significantly less level 2 reasoning than did any other dilemma. Conversely, the Webster dilemma elicited significantly 
more level 2 reasoning and significantly less level 5 reasoning than did any other dilemma. The Heinz dilemma elicited significantly less level 4 reasoning than did other dilemmas while the student dilemma elicited fairly equal amounts of levels $2,3,4,5$ and 6 reasoning. In order to evaluate subjects' individual profiles, ten subjects were randomly selected. These subjects' percentages of responses at levels $2,3,4,5 \mathrm{~A}, 5 \mathrm{~B}$ and 6 are presented in Table 14.

Table 14

Percentages of Stage Level Responses for Ten Randomly Selected Subjects

\begin{tabular}{rrrrrrr} 
Subject & $\underline{2}$ & $\underline{3}$ & $\underline{4}$ & $\underline{5 \mathrm{~A}}$ & $\underline{5 \mathrm{~B}}$ & $\underline{6}$ \\
\hline 1 & 4 & 8 & 24 & 28 & 4 & 4 \\
2 & 12 & 20 & 16 & 20 & 12 & 4 \\
3 & 16 & 16 & 28 & 24 & 8 & 0 \\
4 & 4 & 20 & 16 & 32 & 0 & 4 \\
5 & 4 & 8 & 32 & 32 & 0 & 4 \\
6 & 8 & 16 & 20 & 24 & 0 & 18 \\
7 & 12 & 20 & 36 & 12 & 4 & 0 \\
8 & 4 & 8 & 32 & 12 & 0 & 16 \\
9 & 0 & 12 & 28 & 32 & 8 & 8 \\
10 & 12 & 24 & 16 & 36 & 0 & 0
\end{tabular}

Examination of Table 14 indicates that subjects appear to exhibit a modal level of moral reasoning. Other 


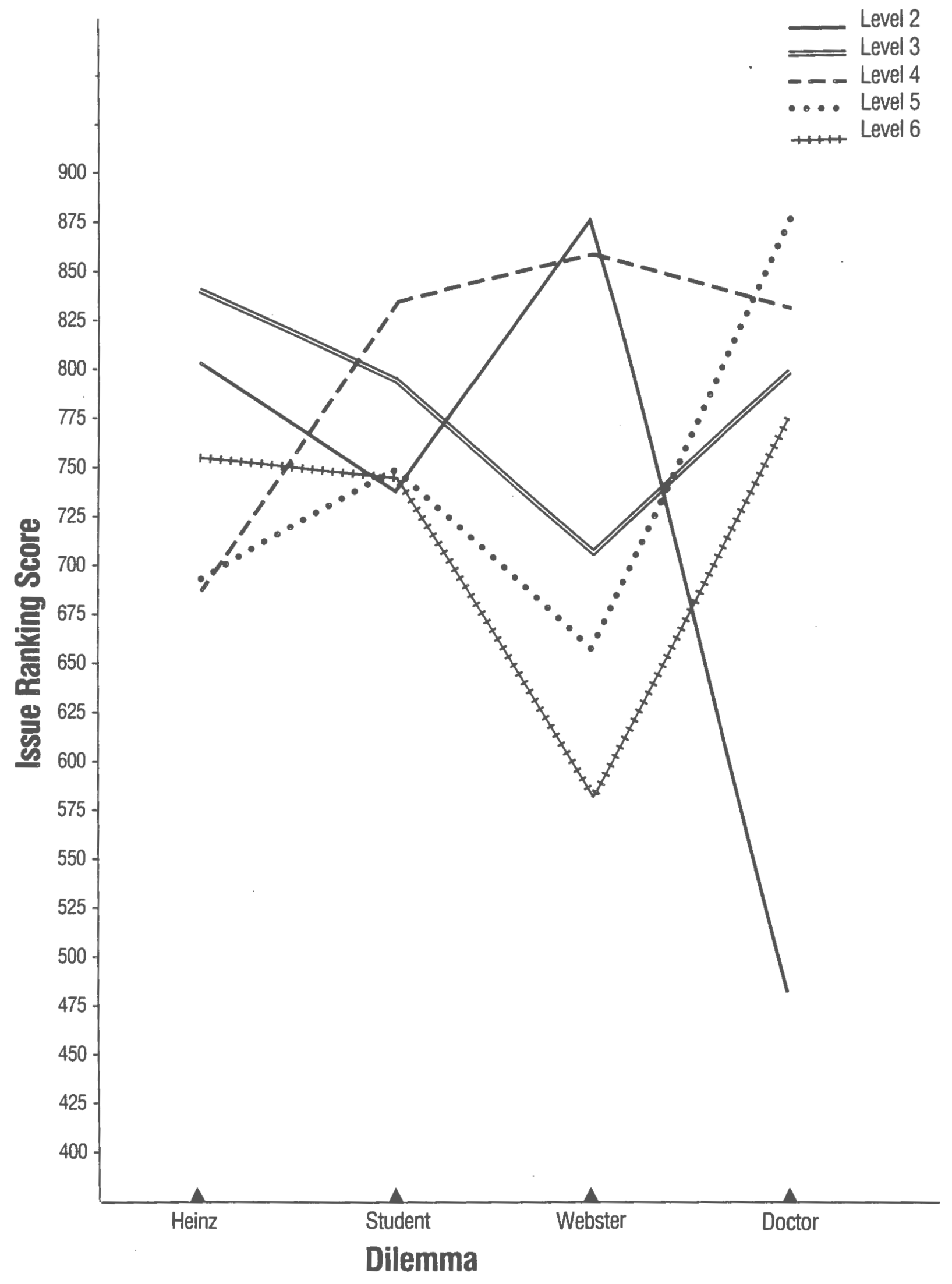

Figure 4. Sum of issue ranking of Heinz, Student, Webster, and Doctor dilemmas across moral reasoning levels 2, 3, 4, 5A, 6 . 
levels of moral reasoning evidence a lesser frequency of usage with a gradual decrease in usage as the levels move away from the modal response.

Thus, the individual profiles are consistent with the complex stage model. These data, however, do not address the assumption of structural whole since the percentages represent data aggregated across all six dilemmas. 
CHAPTER V

Discussion

Various cognitive developmental models have been suggested to explain individuals' reasoning in response to moral dilemmas. Kohlberg, the most influential theorist in the field, has proposed a simple six-stage model of moral reasoning. In Kohlberg's formulation a given stage-response on a task does not represent a specific response determined by knowledge or familiarity with the task. Rather it represents an underlying thought-organization. These thought organizations, which are qualitatively different for each of the six hypothesized stages, are the structured wholes of cognitive moral stage theory. Many researchers have been unable to find empirical support for the underlying assumption of structured whole. Rest, in an attempt to address the sources of the empirical anomalies associated with Kohlberg's model, developed a complex stage model. In Rest's formulation, a subject's responses are hypothesized to evidence a consistent probabilistic pattern, i.e., subjects may demonstrate more than a single stage of reasoning when responding to moral dilemmas, yet this pattern of stages offered in response to dilemmas of diverse content should be consistent across dilemmas. 
While Kohlberg and Rest disagree as to the number of stages subjects will exhibit in response to moral dilemmas, they both hold that the primary determinant of subjects' moral reasoning level are innate cognitive structures rather than the content of the dilemma or other test characteristics or variables.

The purpose of this study was to evaluate the validity of the assumption of structured whole, through a systematic examination of the pattern of responses offered by subjects on the Defining Issues Tests, an instrument frequently used to assess moral development. Prior to this study little research has been done which specifically examines the consistency of subjects' responses across the variables of dilemma and stage. Such research is necessary if the validity of stage theory is to be established.

Analyses of responses to six dilemmas of diverse story content offer no support for the structured whole hypothesis of cognitive moral development theory, nor was a consistent pattern of stages evident. Subjects offered dramatically different levels of moral reasoning in response to the dilemmas of the Defining Issues Test. Dilemmas appear to "pull for" and/or exclude certain levels of moral reasoning differentially. This effect is most striking comparing the Doctor dilemma to the Webster dilemma. The Doctor dilemma appears to exclude Level 2 
reasoning while "pulling for" Level 5 reasoning. Conversely, the Webster dilemma appears to exclude Level 6 reasoning while "pulling for" Level 4 reasoning.

The Student dilemma elicits approximately equal amounts of levels $2,3,4,5$ and 6 reasoning while the Heinz dilemma elicits significantly lesser amounts of levels 4 and 5 reasoning than level 3 reasoning. When performance curves are constructed across dilemmas for levels $2,3,4,5$ and 6 , the lack of consistency in story "pull" becomes evident. Dilemmas elicit markedly different patterns of moral reasoning. This finding offers no support for the assumption of structured whole since the presence of underlying thought patterns controlling moral reasoning behavior would predict consistent profiles across dilemmas.

In assessing the sources of the lack of support these data provide for the assumption of structured wholes, five possible factors must be considered:

1. Scoring Error. In assessing the impact of scoring error on the lack of consistency evidenced by these data it is necessary to examine the DIT itself. Rest claims that the DIT offers several methodological advantages over the semi-structured interview typically used to assess moral reasoning. One of these is "objective" scoring which results in both the minimization of scores bias and scorer error. As a result of the objec- 
tive nature of the DIT, the effect scoring error can most probably be discounted as a source of the lack of consistency in subjects' responses.

2. Measurement Error. While considerable research assessing the psychometric properties of the DIT P-score has been completed, only a limited amount of research has addressed the question of the reliability of stage scores. While the DIT P-score, a measure of subjects' reasoning at the principled levels of moral reasoning (levels 4, 5A, 5B and 6) has been reported to exhibit test-retest reliabilities in the upper .70's and .80's, the stage score reliabilities are considerably lower and evidence much more variation. It is also important to note that since reliability is also a function of test length, it is to be expected that the P-score reliability would be higher than the individual stage score reliabilities. In order to accurately assess the reliability of the test, both the total test and subtest (i.e., stage score) reliabilities must be determined with appropriate size samples. Since stage score reliabilities have not been systematically investigated, the causal agent for the lack of consistency in this study must be interpreted conservatively. The inconsistency in stage scores across dilemmas may be due to either poor stage score reliability or to the absence of an underlying cognitive structure or to a combination of both effects. 
3. Fluctuation Due to Situational Variables. Situational theorists would argue that lack of consistency evidenced in responses is the result of the overwhelming influence of cultural and environmental variables. People are hypothesized to evidence various levels of reasoning as a result of subtle interpretations of the moral dilemma which result from and may depend upon many moderating variables and/or the interactions of such variables. Situational theorists have suggested that some of these variables may be related to either situational or person variables. Flavell and Wohlwill (1969) have pointed out that response variability may stem from differences in factors such as the "stimulus materials and their familiarity, the manner of presentation of the relevant information, the amount of information-load placed on the child and the role played by the cognitive skills of memory and sequential processing of information." In order to assess which variables impact on moral reasoning it is necessary to conduct research in which aspects of test stimuli affect the assessment of moral reasoning and the degree to which each of these factors affects stage scores.

4. Absence of Underlying Cognitive Structure. If an underlying cognitive structure is assessed by a valid and reliable instrument, an overall consistency of moral reasoning level is to be expected. In interpreting the 
meaning of the lack of consistency and its implications for the concept of structured wholes, the following must be considered:

Cognitive-developmental research suggests that subjects are particularly likely to evidence inconsistent responding when they are in transitional stages, i.e., periods of acquiring a new structure. It is during this transitional phase that inconsistencies are to be expected. Thus the lack of consistency in a given subject's responses at a single point in time is not enough to call into question the concept of structure whole from the perspective of either simple stage theory or complex stage theory.

However, since these data report the responses of 255 subjects, an overall consistent pattern of response should have been evident if structured whole is a valid underlying assumption. It is important to note that these 255 subjects as a group may be in transition. As undergraduates in the age range 18 to 24 , such transitional reasoning might be expected.

5. Lack of Content Validity of DIT Items. Lack of consistency in subjects' responses on the DIT may be due to the lack of content validity of the DIT items themselves. Rest offers no empirical or theoretical support for the content validity of items. In order to establish this validity, the DIT must be evaluated by experts in the 
fields of psychology, moral philosophy or theology.

Further, a factor analysis or cluster analysis would add additional data by which to assess the content validity of individual items.

Inspection of Table 14 suggests that subjects do not evidence a unitary stage response, rigorously excluding reasoning at any other level. Subjects appear to evidence a modal response with the next higher and lower stages evidencing a higher frequency of usage than stages further removed from the modal stage. Thus these data do offer some support for the presence of a systematic progression of moral reasoning stages where the attainment, maximum utilization and rejection of stages are predicted to yield a set of overlapping bell-shaped curves. As a result, Rest's complex stage model for moral reasoning is provided some support.

In summary, the findings of this study do not support the presence of an underlying cognitive structure cross-cutting all moral dilemas. The validity of the structured whole assumption is questioned. Subjects appear to reason differentially with certain dilemmas eliciting significantly higher or lower reasoning than other dilemmas. This finding offers some support to the contention of situational theorists that the characteristics of the dilemma significantly affect the reasoning offered by individuals. Individuals' reasoning on one 
moral task may not be used unitarily as a predictor for reasoning on another.

Limited evaluation of individual subjects' patterns of responses on the DIT offers some support for the complex stage model of moral reasoning. Additional research in the following three areas is necessary in order that the underlying assumptions of cognitive developmental theory be further investigated:

1. Determination of the Test-Retest Reliability of the DIT Stage Scores. Since the absence or presence of consistency in stage scores is the crux of the issue, the instrument used to assess stage score must be a valid and reliable measure of stage score. Thus additional research must be undertaken to determine the psychometric properties of the DIT stage scores.

2. Profile Analysis of Subject's Response on the DIT. In order to assess whether the complex stage model accurately represents moral reasoning, a profile analysis should be conducted to determine the match between the theory and empirical data.

3. Finally, research is necessary to clarify which variables impact upon moral reasoning. Consideration must be given to both subject and dilemma variables and possible interaction of these variables. 


\section{LIST OF REFERENCES}

Armsby, R.E. (1971). A re-examination of the development of moral judgements in children. Child Development, 42, 1241-1248.

Baldwin, C.P., \& Baldwin, A.L. (1970). Children's judgement of kindness. Child Development, 41, 30-47.

Berg-Cross, L.G. (1975). Intentionality, degree of damage, and moral judgements. Child Development, 46, 970-974.

Berndt, T.J., \& Berndt, E.G. (1975). Children's use of intentionality in person perception and moral judgement. Child Development, 46, 904-912.

Bode, J., \& Page, J. (1978). Comparison of measures of moral judgement. Psychological Reports, 43, 307-312.

Brainerd, C.J. (1978). Piaget's theory of intelligence. Princeton, NJ: Prentice-Hall.

Buchanan, J.P., \& Thompson, S.K. (1973). A quantitative methodology to examine the development of moral judgement. Child Development, 44, 186-189.

Chandler, M.J., Greenspan, S., \& Barenboim, C. (1973). Judgement of intentionality in response to video taped and verbally presented moral dilemmas: the medium is the message. Child Development, 44, $315-320$.

Colby, A., Gibbs, J., \& Lieberman, M. (1983). A longitudinal study of moral judgement. Monograph of the Society for Research in Child Development, 48 (4).

Collins, W.A. Berndt, T.J., \& Hess, V.L. (1974). Observational learning of motives and consequences for television aggression: a developmental study. Child Development, 45,799-802.

Crockenberg, S., \& Nicolaryev, M. (1977). Stage transition in moral reasoning as related to conflict experienced in naturalistic settings. Unpublished manuscript, University of California at Davis.

Edwards, C.P. (1982). Moral development in comparative cultural perspectives. In D. Wagner \& H.W. Stevenson (Eds.), Cultural perspectives on child development. (pp. 80-101). San Francisco: Freeman. 
Flavell, J.H., \& Wohlwill, J.F. (1969). Formal and functional aspects of cognitive development. In D. Elkind \& J.H. Flavell (Eds.), Studies in cognitive development: Essays in honor of Jean Piaget. (pp. 60-120). New York: Oxford University Press.

Hartshorne, H., \& May, M.A. (1928). Studies in the nature of character. Vol. 1: Studies in deceit. New York: Macmillan.

Hoffman, M.L. (1970). Moral development. In P. Mussen (Ed.), Carmichael's manual of child psychology, Vol. 2. New York: Wiley.

Irwin, D.M., \& Moore, S.G. (1971). The young child's understanding of social justice. Developmental Psychology, $5,406-410$.

Johnson, R.C. (1972). A study of children's moral judgements. Child Development, 33, 317-354.

Kohlberg, L. (1967). Moral and religious education and the public schools: A developmental view. In T. Sizer (Ed.) Religion and public education. (pp. 60-98). Boston: Houghton-Mifflin.

Kohlberg, L. (1969). Stage and sequence: The cognitive-developmental approach to socialization. In D. Goslin (Ed.), Handbook of Socialization Theory and Research. (pp. 347-480). Chicago: Rand McNally.

Kohlberg, L. (1971). From is to ought: How to commit the naturalistic fallacy and get away with it in the study of moral development. In T. Mischel (Ed.), Cognitive Development and Epistemology. (pp. 151-235). New York: Academic Press.

Kohlberg, L. (1973). Collected papers on moral development and moral education. Cambridge: Harvard University Press.

Kohlberg, L. (1980). Essays on moral development. New York: Rand, McNally.

Kohlberg, L. (1984). Essays on moral development: Vol. 2. The psychology of moral development. San Francisco: Harper \& Row.

Kohlberg, L., Colby, A., Gills, J., \& Speicher-Dubin, E. (1976). Moral stage scoring manual. Cambridge: Center for Moral Education, Harvard University. 
Leming, J.S. (1978). Cheating behavior, situational influence, and moral development. Journal of Educational Research, 71, 214-217.

Lieberman, M. (1971). Estimation of a moral judgement level using items whose alternatives form a graded scale. Unpublished doctoral dissertation, University of Chicago.

Magowan, S.A., \& Lee, T. (1970). Some sources of error in the use of the projective method for the assessment of moral judgement. British Journal of Psychology, 61, 535-543.

MCGeorge, C.M. (1974). Situational variation in level of moral judgement. British Journal of Educational Psychology, 44, $11 \overline{6-122}$.

Medinnus, G.R. (1959). Immanent justice in children: A review of the literature and additional data. Journal of Genetic Psychology, 94, 253-262.

Piaget, J. (1960). The general problem of the psychobiological development of the child. In J.M. Tanner \& B. Inhelder (Eds.), Discussions on child development: Vol. 4. New York: International Universities Press.

Piaget, J. (1965). The moral judgement of the child (M. Gabain, Trans.). New York: The Free Press. TOriginal work published 1932.)

Plummer, K. (1982). Review and evaluation of two models of moral development. Unpublished masters thesis, University of Rhode Island.

Plummer, K. (1983). A structural-functional model of moral development. Unpublished doctoral dissertation, University of Rhode Island.

Rest, J.R. (1979). Development in judging moral issues. Minneapolis: University of Minnesota Press.

Rest, J.R., Cooper, D., Coder, R., Masanz, J., \& Anderson, D. (1974). Judging the important issues in moral

dilemmas -- an objective test of development. Developmental Psychology, 10, 491-501.

Shanty, D.W., \& Voydanoff, D.A. (1973). Situation effects on retaliatory aggression at three age levels. Child Development, 44, 149-153. 
Simpson, E.L. (1974). Moral development research: A case of scientific cultural bias. 'Human Development, 17. 81-106.

Vitro, F.T. (1969). The effects of probability of test success, opportunity to cheat and test importance on the incidence of cheating. Unpublished doctoral dissertation, University of Iowa. 
Append ix A 
INSTITUTIONAL REVIEW BOARD

REPORT OF ACTION

Title of Proposal: Effects of the content of moral dilemmas upon subjects responses on the Defining Issues Test.

Principal Investigator: Gail Maria Lawson

This is to certify that the application identified above has been reviewed by the Board approved to review proposals for research and other activities involving human subjects.

DATE OF REVIEW: March 1, 1984

COMMITTEE ACTION: Approved

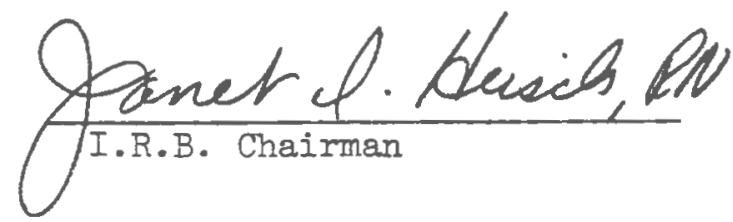

cc: Department Chairman, Dr. A. Lott Coordinator of Research I.R.B. File 
Append IX B 
This questionnalre is almed at understanding how people think about soclal problems. Different people often have different opinlons about questlons of right and wrong. There are no "rIght" answers in the way that there are rlght answers to math problems. We would llke you to tell us what you think about several problem storles. The papers will be fed to a computer to find the average for the whole group, and no one will see your Individual answers.

Please glve us the followlng Information:

Name

Age Class and perlod femal $\theta$

School

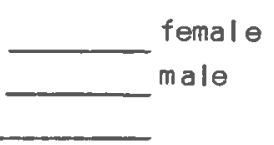

In this questionnalre you wlII be asked to give your op Inlons about several storles. Here is a story as an example. Read it, then turn to the next page.

Frank Jones has been think Ing about buylng a car. He Is marrled, has two small chlidren and earns an average Income. The car he buys will be his famlly's only car. it will be used mostly to get to work and drive around town, but sometimes for vacatlon trips also. In trylng to declde what car to buy, Frank Jones reallzed that there were a lot of questions to consider. On the next page there is a list of some of these questions.

If you were Frank Jones, how Important would each of these questlons be in deciding what car to buy? 
PART A. (SAMPLE)

On the left hand side of the page check one of the spaces by each question that could be considered.

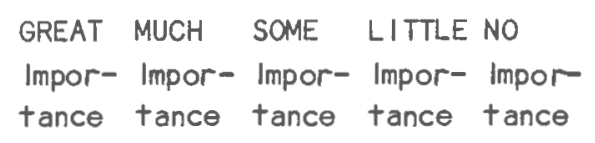

2. Would a used car be more economical in the long run than a new car.

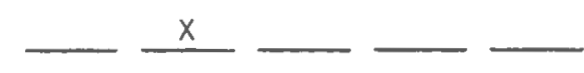

3. Whether the color was green, Frank's favorite color.

X 4hether the cubic Inch displacement was at least 200.

5. Would a large, roomy car be better than a compact car.

6. Whether the front were differential.

\section{PART B. (SAMPLE)}

From the list of questions above, select the most important one of the whole group. Put the number of the most Important question on the top line below. Do Il kewise for your 2nd, 3rd and 4th most important choices.

\begin{tabular}{l} 
Most Important \\
Second most Important \\
Third most important \\
Fourth most Important \\
\hline
\end{tabular}


HEINZ AND THE DRUG

In Europe a woman was near death from a special kind of cancer. There was one drug that the doctors thought might save her. It was a form of radium that a druggist in the same town had recently discovered. The drug was expensive to make, but the drugglst was charging ten times what the drug cost to make. He paid $\$ 200$ for the radium and charged $\$ 2000$ for a small dose of the drug. The slck woman's husband, He inz, went to everyone he knew to borrow the money, but he could only get together about \$1000, which is half of what it cost. He told the druggist that his wife was dying, and asked him to sell it cheaper or let hIm pay later. But the drugglst said, "No, I discovered the drug and I'm golng to make money from 1t." So Helnz got desperate and began to think about break ing into the man's store to steal the drug for his wife.

Should Helnz steal the drug? (Check one) Should steal it Can't decide Should not steal it 
HEINZ STORY

On the left hand slde of the page check one of the spaces by each question to indicate its importance.
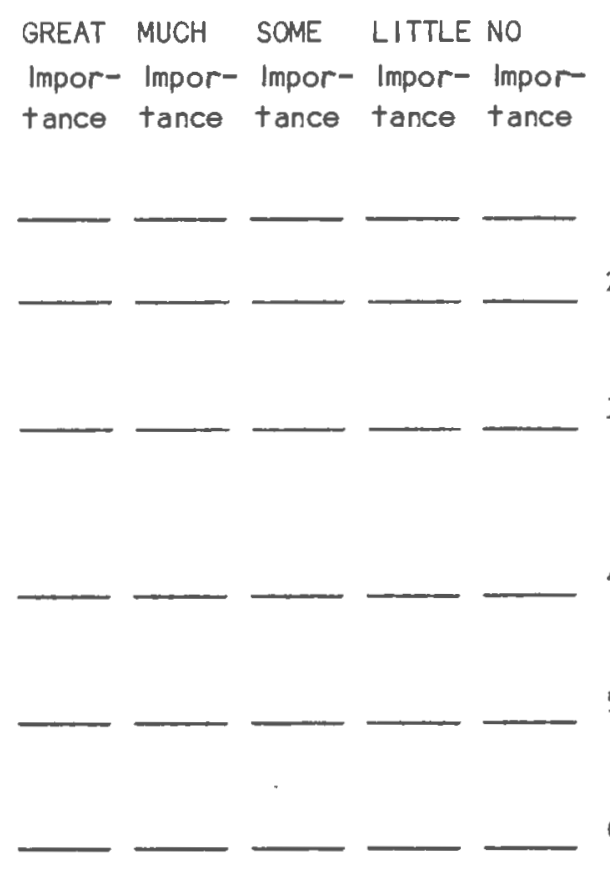

1. Whether a community's laws are golng to be upheid.

2. Isn't it only natural for a loving husband to care so much for his wife that he's steal?

3. Is Hinz wllling to risk getting shot as a burglar or golng to jall for the chance that stealing the drug might help?

4. Whether Heinz is a professlonal wrestler, or has consider influence with professional wrestlers.

5. Whether Heinz is stealing for himself or doing this solely to help someone else.

6. Whether the druggist's rights to his invention have to be respected.

7. Whether the essence of living is more encompassing than the termination of dying, soclally and individually.

8. What values are going to be the basis for governing how people act towards each other.

9. Whether the druggist is going to be allowed to hide behind a worthless law which only protects the rich anyhow.

10. Whether the law in this case is getting in the way of the most basic clalm of any member of soclety.

11. Whether the druggist deserves to be robbed for belng so greedy and cruel.

12. Would stealing in such a case bring about more total good for the whole soclety or not.

From the Ilst of questions above, select the four most important:

Most Important

Second most important

Third most important

Fourth most important 


\section{STUDENT TAKE-OVER}

At Harvard University a group of students, called the Students for a Democratic Society (SDS), belleve that the Unlversity should not have an army ROTC program. SDS students are against the war in Viet Nam, and the army training program helps send men to fight In Vlet Nam. The SDS students demanded that Harvard and the army ROTC tralning program as a university course. This would mean that Harvard students could not get army training as part of their regular course work and not get credit for it towards their degrees.

Agreeing with the SDS students, the Harvard professors voted to end the ROTC program as a university course. But the President of the University stated that he wanted to keep the army program on campus as a course. The SDS students felt that the President was not going to pay attention to the faculty vote or to their demands.

So, one day last April, two hundred SDS students walked Into the university's adminlstration bullding and told everyone else to get out. They sald they were doing this to force Harvard to get rid of the army training program as a course.

Should the students have taken over the administration building? (Check one) Yes, they should take It over Can't decide No, they should not take it over 
STUDENT TAKE-OVER
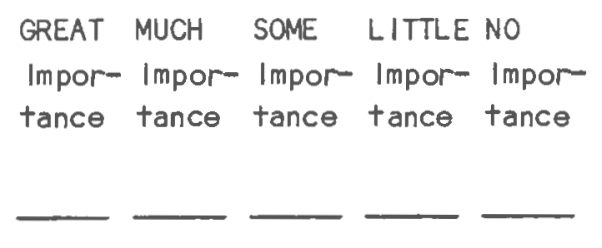

1. Are the students doing this to really help other people or are they doing it for kicks.

2. Do the students have any right to take over property that doesn't belong to them.

3. Do the students reallze that they might be arrested and fined, and even expelled from school.

4. Would taking over the bullding in the long run benefit more people to a greater extent.

5. Whether the president stayed within the IImIts of his authority in Ignoring the faculty vote.

6. Will the takeover anger the public and give all students a bad name.

7. Is taking over a building consistent with principles of justice.

8. Would allowing one student take-over encourage many other student take-overs.

9. Did the president bring this $\mathrm{m}$ Isunderstanding on himself by being so unreasonable and uncooperative.

10. Whether running the unlversity ought to be in the hands of a few administrators or in the hands of all the people.

11. Are the students following principles which they belleve are above the law.

12. Whether or not university declsions ought to be respected by students.

From the list of questions above, select the four most Important:

Most Important

Second most important

Third most important

Fourth most Important

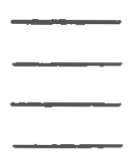




\section{ESCAPED PRISONER}

A man had been sentenced to prison for 10 years. After one year, however, he escaped from prison, moved to a new area of the country, and took on the name of Thompson. For 8 years he worked hard, and gradually he saved enough money to buy his own business. He was fair to his customers, gave his employees top wages, and gave most of his own profits to charity. Then one day Mrs. Jones, an old nelghbor, recognized him as the man who had escaped from prison 8 years before and whom the police had been looking for.

Should Mrs. Jones report Mr. Thompson to the pollice and have hIm sent back to prison? (Check one) Should report $\mathrm{h} / \mathrm{m}$ Can't decide Should not report $\mathrm{hlm}$ 


\section{ESCAPED PRISONER}

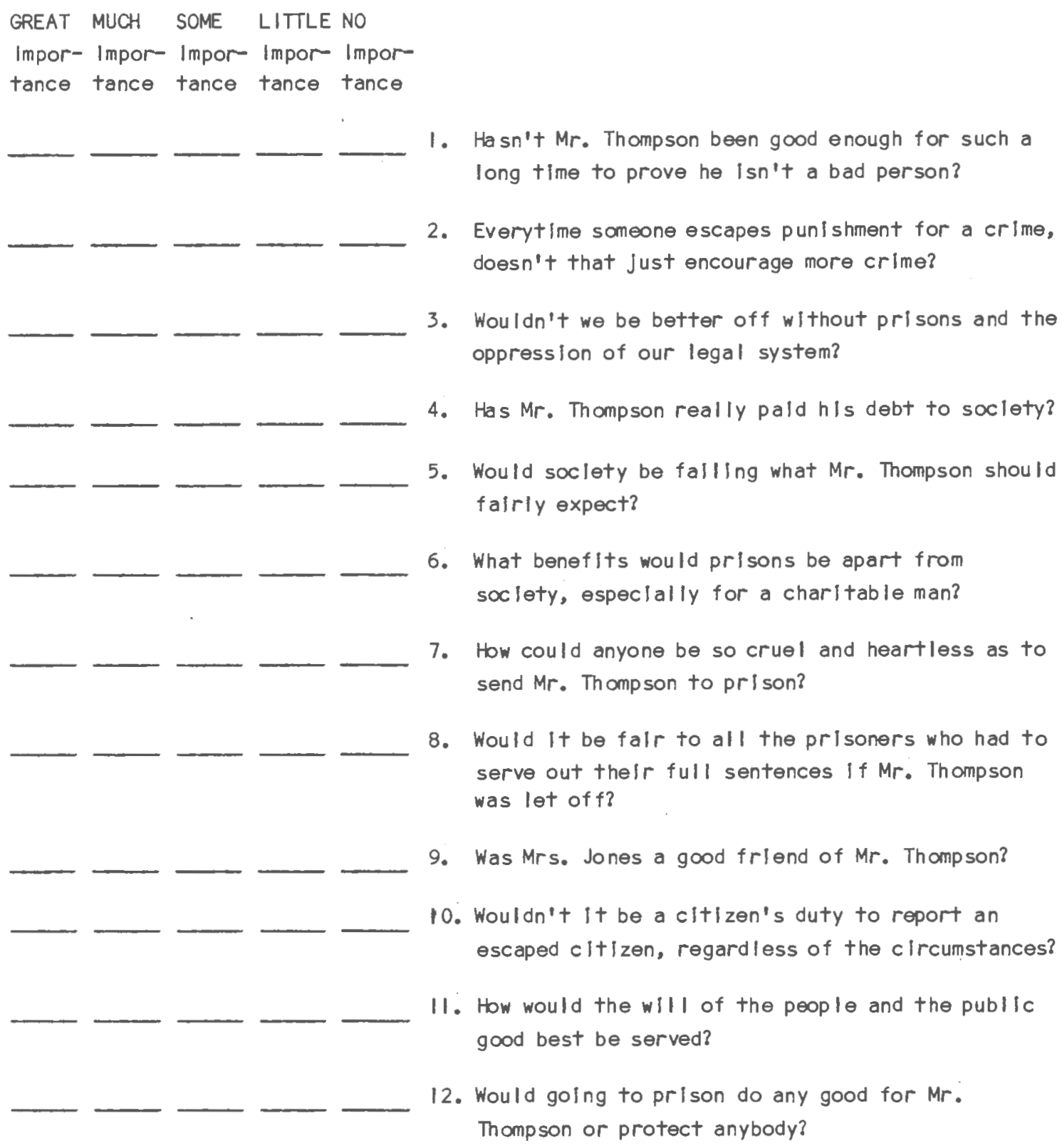

From the list of questions above, select the four most important:

Most Important

Second most Important

Third most important

Fourth most Important 
NEW PAPER

Fred, a senlor in high school, wanted to publish a mimeographed newspaper for students so that he could express many of his opinions. He wanted to speak out agalnst the war in Viet Nam and to speak out against some of the school's rules, like the rule forbldding boys to wear long halr.

When Fred started his newspaper, he asked his principal for permission. The principal sald it would be all right if before every publication Fred would turn In all his articles for the princlpal's approval. Fred agreed and turned in several articles for approval. The principal approved all of them and Fred published two issues of the paper in the next two weeks.

But the principal had not expected that Fred's newspaper would recelve so much attention. Students were so excited by the paper that they began to organlze protests against the hair regulation and other school rules. Angry parents objected to Fred's opinions. They phoned the principal telling him that the newspaper was unpatriotic and should not be published. As a result of the rising excitement, the principal ordered Fred to stop publlshing. He gave a reason that Fred's activitles were disruptive to the operation of the school.

Should the principal stop the newspaper? (Check one) Should stop it Can't decide Should not stop it 
NEW SPAPER

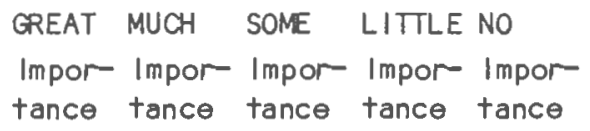

- Is the principal more responsible to students or to parents?

2. Did the principal give his word that the newspaper could be published for a long time, or did he just promise to approve the newspaper one issue at a time?

3. Would the students start protesting even more if the principal stopped the newspaper?

4. When the welfare of the school is threatened, does the principal have the right to glve orders to students?

5. Does the principal have the freedom of speech to say "no" in this case?

6. If the princlpal stopped the newspaper would he be preventing full discussion of important problems?

7. Whether the princlpal's order would make Fred lose faith in the principal?

8. Whether Fred was really loyal to $h$ is school and patriotic to his country.

9. What effect would stopping the paper have on the student's education in critical thinking and judgment?

10. Whether Fred was in any way violating the rights of others in publishing his own opinions.

11. Whether the princlpal should be Influenced by some angry parents when it is the principal that knows best what is golng on in the school.

12. Whether Fred was using the newspaper to stir up the hatred and discontent.

From the list of questions above, select the four most important:

Most Important

Second most important

Th Ird most important

Fourth most important 
WEBSTER

$\mathrm{Mr}$. Webster was the owner and manager of a gas station. He wanted to hlre a nother mechanic to help him, but good mechanlcs were hard to find. The only person he found who seemed to be a good mechanic was Mr. Lee, but he was Chinese. While Mr. Webster himself didn't have anything against Orlentals, he was afrald to hire Mr. Lee because many of his customers didn't like orlentals. His customers might take their business elsewhere if Mr. Lee was working in the gas station.

When Mr. Lee asked Mr. Webster if he could have the job, Mr. Webster said that he had already hired somebody else. But Mr. Webster really had not hired anybody, because he could not find anybody who was a good mechanic besides Mr. Lee.

Should the princlpal stop the newspaper? (Check one) Should have hired $\mathrm{Mr}$. Lee Can't declde Should not have hired him 
WEBSTER
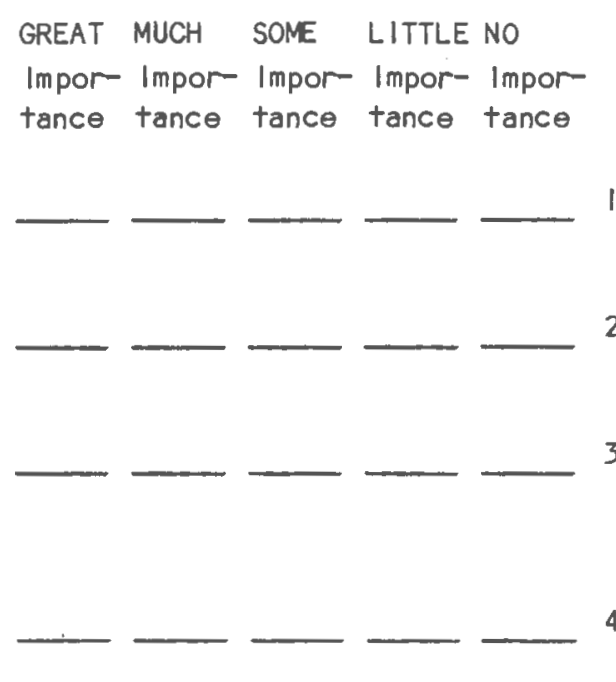

1. Does the owner of a bus iness have the right to make his own business decislons or not?

2. Whether there is a law that forbids raclal discrimination in hiring for jobs.

3. Whether Mr. Webster is prejudiced against orlentals himself or whether he means nothing personal in refusing the job.

4. Whether hiring a good mechanlc or paying attention to his customers' wishes would be best for his business.

5. What individual differences ought to be relevant in deciding how society's roles are fllled?

6. Whether the greedy and competitive capitalistic system ought to be completely abandoned.

7. Do a majority of people in Mr. Webster's soclety feel like his customers or are a majorlty against prejudice?

8. Whether hlring capable men IIke Mr. Lee would use talents that would otherwlse be lost to soclety.

9. Would refusing the job to Mr. Lee be consistent with Mr. Webster's own moral bel lefs?

10. Could Mr. Webster be so hard-hearted as to refuse the job, knowing how much it means to Mr. Lee?

11. Whether the Christlan commandment to love your fellow man applies to this case.

12. If someone's In need, shouldn't he be helped regardless of what you get back from him?

From the list of questions above, select the four most important:

Most Important

Second most Important

Third most Important

Fourth most Important

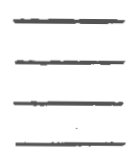


THE DOCTOR'S DILEMMA

A lady was dying of cancer which could not be cured and she had only about six months to live. She was in terrible pain, but she was so weak that a good dose of pain-k lller like morphine would make her die sooner. She was delirlous and almost crazy with pain, and in her calm perlods, she would ask the doctor to give her enough morphine to kill her. She said she couldn't stand the pain and that she was going to die in a few months anyway.

Should the doctor do? (Check one)

He should give the lady an overdoes that will make her dle Can't decide

Should not give her an overdose 
DOCTOR

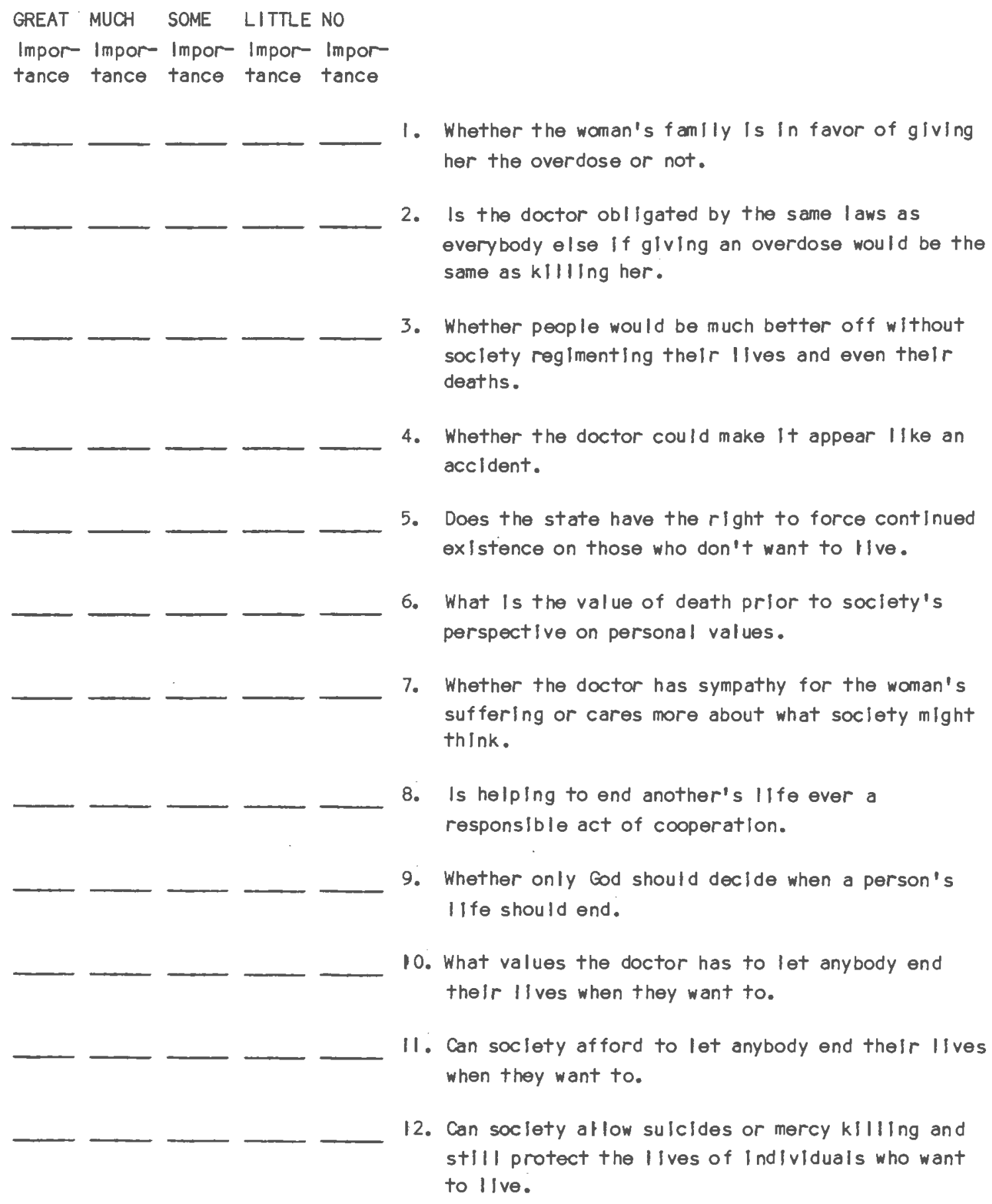

3. Whether people would be much better off without soclety regimenting their I ives and even their deaths.

- Whether the doctor could make It appear I/ke an accident.

Does the state have the right to force continued existence on those who don't want to live.

What is the value of death prior to society's perspective on personal values.

Whether the doctor suffering or cares more about what soclety might think.

. Is helping to end another's IIfe ever a responsible act of cooperation.

Whether only cod should decide when a person's ife should end.

What values the doctor has to let anybody end their lives when they want to.

- Can soclety afford to let anybody end their lives when they want to. still protect the Ilives of Individuals who want to Iive.

From the llst of questions above, select the four most important:

Most Important

Second most important Third most important

Fourth most important 
Append IX C 
Defining Issues Test Standard Test Instructions

Please read the cover sheet of the Opinions About Social Problems. If you have any questions please ask. In this questionnaire you will be asked to give your opinions about several stories. There are no right or wrong answers. Please turn tc the first page and begin. 
Table $0-1$

Tukey Procedure Assoclated with Levels of Moral Reasoning for

DI lemma Is sue Ranking Totals

$\underline{\text { Level } 2}$

Doctor

Student

Helnz

Webster

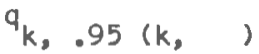

( $n$ ms $\underset{\text { error }}{ })(q .95 \mathrm{k}$, )

${ }^{*} p$

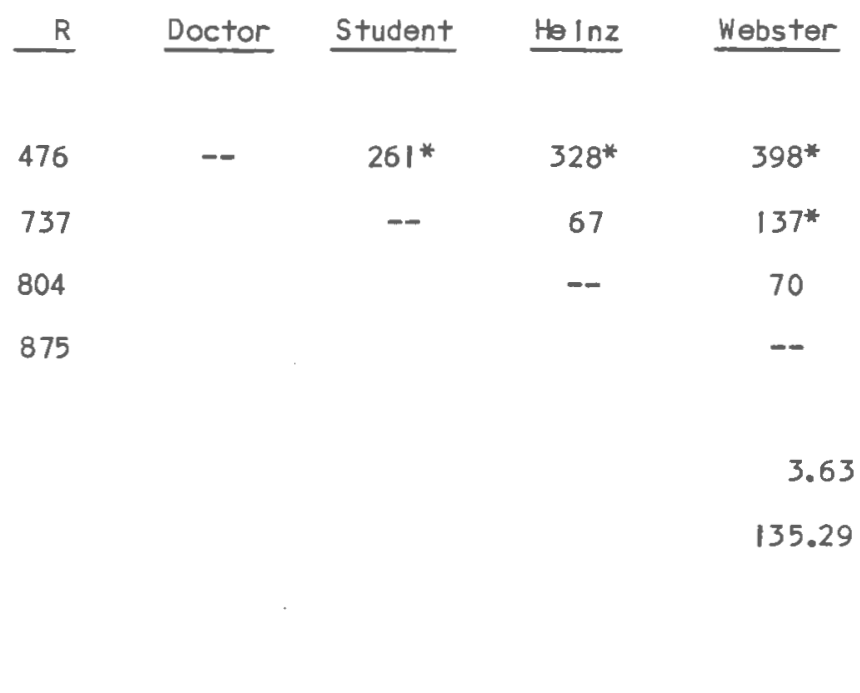

R Webster Student Doctor He Inz

706

87

93

104

793

$--$

6

47

799

--

41

He Inz

840

$q_{k}, .95(k, \quad)$

(n ms error $)(q .95 k$, )

${ }^{*} \underline{p}-.05$. 
Level 4

Ho $\ln z$

Student

Doctor

Webster

$q_{k}, .95(k$,

( $n$ ms error $)(q .95 \mathrm{k}$, )

*p. .05.

Level 5

Webster

$H_{\theta} \ln z$

Student

Doctor

$q_{k, .95}(k, \quad)$

(nms error $)(q .95 \mathrm{k}$, )

* $\quad .05$.

Level 5

Webster

He $\ln z$

Student

Doctor

$q_{k}, .95(k$,

860

686

830

833

\section{$\mathrm{Helnz}$}

Student

$144^{*}$

$147^{*}$

$174^{*}$

3

30

21

3.63

135.29

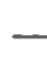

R

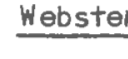

Ho In

32

$--$

748

874

$-$

\section{R Webster Helnz Student Doctor}

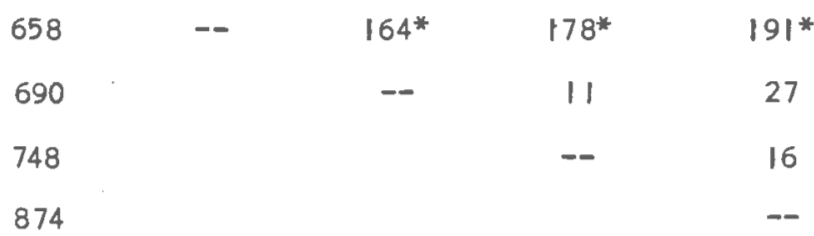
135.29

${ }^{*} \underline{p} \quad .05$. 
Table D-2

Tukey Procedure Assoclated with Defining Is sues Test DIlemmas for

Levels of Reasoning Is sue Ranking Totals

Helnz Dl lemma

R Level 4 Level 5 Level 6 Level 2 Level 3

Level 4

686

$-$

68

118

$272^{*}$

Level 5

690

64

114

$150^{*}$

Level 6

754

- 50

86

Level 2

804

$--\quad--$

36

Level 3

840

$q_{k}, .95(k, \quad)$

3.86

( $n$ ms error $)(q .95 \mathrm{k}$, )

143.86

* $\quad .05$.

Student DI lemma

R Level 2 Level 6 Level 5 Level 3 Level 4

Level 2

\section{7}

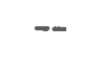

6

11

56

93

Level 6

743

$-$

5

50

87

Level 5

748

$--$

45

82

Level 3

793

$-$

--

37

Level 4

830

$q_{k, .95}(k, \quad)$

( $n$ ms $\underset{\text { error }}{ })(q .95 k$, )

143.86

*. .05 . 


\begin{tabular}{|c|c|c|c|c|c|c|}
\hline Webster DI lemma & $\mathrm{R}$ & Level 6 & Level 5 & Level 3 & Level 4 & Level \\
\hline Level 6 & 579 & -- & 19 & 127 & $281^{*}$ & $295^{*}$ \\
\hline Level 5 & 658 & & -- & 48 & $202^{*}$ & $216^{*}$ \\
\hline Level 3 & 706 & & & $-\infty$ & $154^{*}$ & $168^{*}$ \\
\hline Level 4 & 860 & & & -- & - & 16 \\
\hline Level 2 & 874 & & & & & \\
\hline$q_{k}, .95(k)$, & & & & & 3.86 & \\
\hline (n ms error $)(q .95 k$, & ) & & & & 143.86 & \\
\hline
\end{tabular}

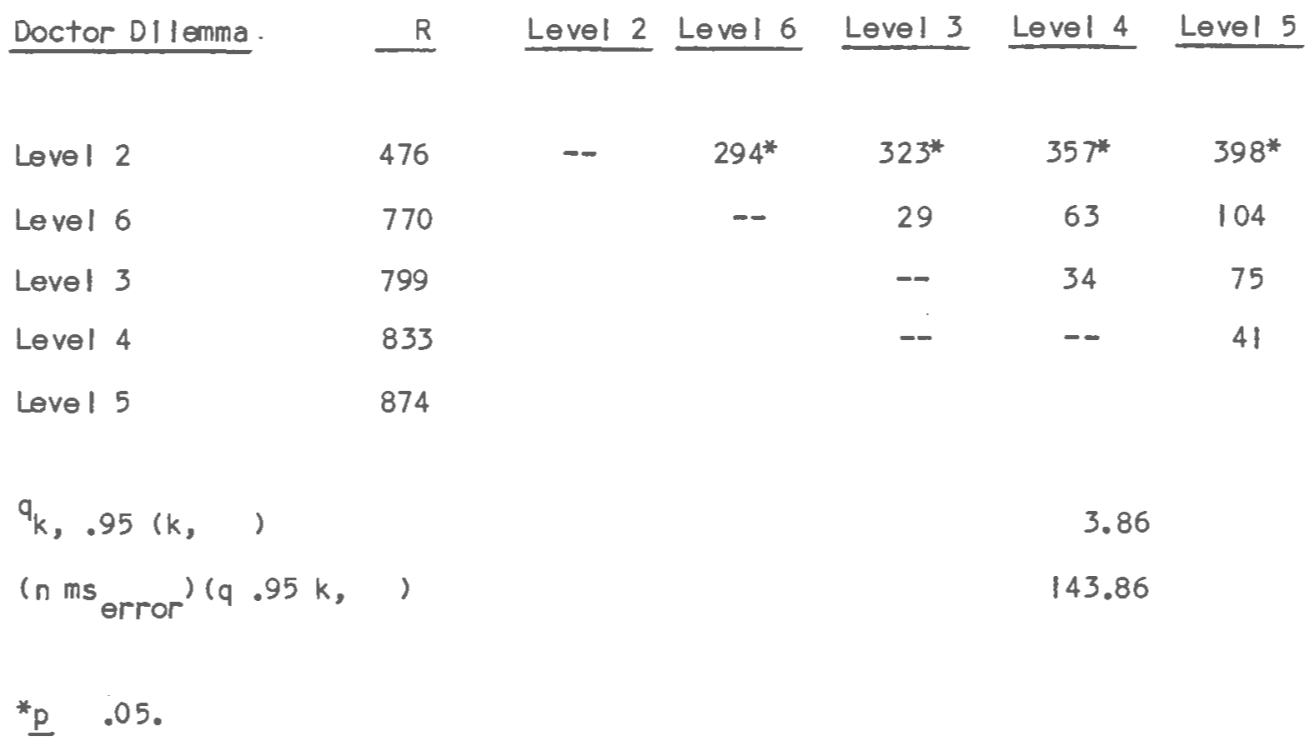

